\title{
The virgin coconut oil (VCO) emulsion powder characteristics: effect of pickering emulsion with microcrystalline cellulose (MCC) and different drying techniques
}

\author{
Bambang Nurhadi ${ }^{1, *}$, Selly Selly ${ }^{2}$, Siti Nurhasanah", Rudy Adi Saputra ${ }^{1}$, Heni Radiani Arifin ${ }^{1}$ \\ ${ }^{1}$ Faculty of Agricultural Industrial Technology, Universitas Padjadjaran, Indonesia \\ ${ }^{2}$ Department of Food Industrial Technology, Universitas Padjadjaran, Indonesia
}

*Corresponding Author: Bambang Nurhadi, Faculty of Agricultural Industrial Technology, Universitas Padjadjaran, Indonesia. Email: bambang.nurhadi@unpad.ac.id

Received: 11 August 2021; Accepted: 21 December 2021; Published: 8 February 2022

(c) 2022 Codon Publications

OPEN ACCESS (C) (1) (2)

PAPER

\begin{abstract}
Virgin coconut oil (VCO) has many health benefits; however, drinking of VCO directly is still uncommon. In order to overcome this problem, microencapsulation can be one of the solutions. Unfortunately, emulsion is an unstable system and rapidly separates into two layers. Therefore, in this study, we carried out the explanatory research of microencapsulation process with descriptive analysis. It comprised two emulsion treatments, using homogenization method, and three drying techniques, to determine the effect of Pickering emulsion with microcrystalline cellulose (MCC) and different drying techniques on the characteristics of VCO powder (before drying: creaming index and emulsion droplet size; and after drying: drying yield, color intensity, moisture content, particle morphology, microencapsulation efficiency, peroxide value, rehydration particle size, and dissolving time). The results demonstrated that all emulsion treatments did not depict any emulsion instability up to 21 days of storage, and the obtained VCO powders had different characteristics. The highest microencapsulation efficiency was $33.49 \pm 1.59 \%$, obtained from the emulsion using Tween 80 and MCC by spray drying, and the lowest peroxide value was $0.464 \pm 0.084 \mathrm{mEq} \mathrm{O}_{2} / \mathrm{kg}$, obtained from the emulsion using Tween 80 and MCC by vacuum drying. The future application of this study is expected to produce $\mathrm{VCO}$ powder that can improve the ease handling of VCO and also commercialize for being used as a non-dairy creamer.
\end{abstract}

Keywords: drying techniques, microcrystalline cellulose, microencapsulation, pickering emulsion, virgin coconut oil

\section{Introduction}

Virgin coconut oil (VCO) is well known for being rich in ingredients that are suitable as functional foods. VCO contains about $90 \%$ saturated fatty acids and about $10 \%$ unsaturated fatty acids (Nurhasanah et al., 2019). There are lots of medium chain triglycerides (MCTs) in these saturated fatty acids consisting of caprylic acid (C8:0), capric acid (C10:0) and lauric acid (C12:0). These MCTs are 'unique' due to their physicochemical properties that have shorter chains (6-12 hydrocarbons) and smaller molecular weight compared to long-chain triglycerides (LCT) (13-21 hydrocarbons), making them absorbed and hydrolyzed faster in the body, resulting in rapidly oxidized and producing higher energy (Nurhasanah et al., 2019; Parrish, 2017). VCO, compared to copra oil, increases high-density lipoprotein (HDL) and lowers low-density lipoprotein (LDL) significantly, and does not cause coronary heart disease because of the absence of trans fatty acids. Besides the above-mentioned major components, there are also tocopherols, $\beta$-carotenes and other phenolic compounds, which are the minor components found in almost all types of vegetable oils, including VCO that has better antioxidant capacity than bleached, refined and deodorized coconut oil. Thus, VCO lowers cholesterol level in the human body, increases 
endurance, accelerates recovery rate, activates anti-aging hormones, and prevents cancer, obesity, dementia, heart attack and other diseases associated with premature aging (Hee et al., 2017). These are the reasons for using VCO for emulsion.

Unfortunately, the limited use of VCO in food products is due to its liquid form, which complicates the transportation and storage process. It solidifies at room temperature with ease under its melting point (Patil et al., 2016). In addition, only a few people consume VCO directly because of people's perception that it is difficult to accept oil consumption (Hee et al., 2015). Therefore, it is necessary to process VCO into a more convenient form for general consumption and its wide application in food products while protecting its bioactive components.

Microencapsulation is a method used to solve problems by giving a new perception to the public. Microencapsulation masks the oily taste in the mouth so that it does not leave the unpleasant taste in throat, extends the shelf life to reduce loss during distribution and storage, leads to easy handling, and increases the solubility and bioavailability of bioactive components (Nedovic et al., 2011). The process of microencapsulation consists of two stages, which are mixing the core material with the coating material to form an emulsion, followed by drying the formed emulsion (Amaral et al., 2019). In this study, mechanism of Pickering emulsion was used for emulsion formation. Pickering emulsion has many advantages, especially it being surfactant-free, having high stability against coalescence, and ostwald ripening (Díaz et al., 2020). High stability against coalescence is a major benefit of stabilization using solid particles, with solid particles partially wetted by each of the liquid phases, that is oil and water phases (partial dual wettability) so that the particles are absorbed at the oil and water interface to form a mechanical barrier, which reduces the tendency of flocculation (Xie et al., 2019). Pickering emulsion also has advantages in terms of its use in smaller quantities, efficiency, easy of using, good oil retention in dry powder, difficult to extract the surface oil, and not susceptible to environmental changes (Bai et al., 2018). That is why, in recent times Pickering emulsion has been widely developed and applied to products, especially to dry products.

Microcrystalline cellulose (MCC) is the solid particle used for Pickering emulsion in this study. MCC has the advantages of having natural ingredients, biocompatibility and biodegradability (Alavi, 2019), and has important functions in preventing emulsion instability (Costa et al., 2019). Also, MCC in the emulsion system has the advantage of being able to withstand to high temperatures so that the emulsion system is more stable when exposed to heat during the drying process. In addition, MCC has been used often in food processing compared to cellulose nanocrystals $(\mathrm{CNC})$ because $\mathrm{CNC}$ is more expensive and both of them could stabilize the emulsion system. The emulsion formation was carried out in two treatments using homogenization method. MCC was added directly to the coarse emulsion because it stabilizes the emulsion system without the help of surfactants (Costa et al., 2019). Besides MCC, Tween 80 with the hydrophile-lipophile balance (HLB) value of 15 was also used as an additional surfactant to MCC because the combination of these emulsifiers could increase the stability of emulsion for a longer period compared to using the surfactant alone $(\mathrm{Hu}$ et al., 2015). Maltodextrin was used as a glass maker in this study. Maltodextrin has rapid dispersion, high water solubility and low viscosity, strong flavor-binding ability, and is able to form an amorphous glass matrix network to protect the core material so as to facilitate drying process and maintain VCO stability against oxygen (Klinjapo and Krasaekoopt, 2018; Muhamad et al., 2018). However, since maltodextrin exhibits poor emulsifying capacity, it is usually combined with other ingredients to maintain emulsion stability (Klinjapo and Krasaekoopt, 2018).

Drying process of emulsion commenced after the emulsion system was formed. Spray drying is one of the drying techniques that is widely used in the food industry (Rajabi et al., 2015). This technique uses continuous high temperature and pressure to produce the final product in the form of a dry powder with a very short contact time between the hot air and the product; therefore, it is safe to dry the VCO that contains bioactive components (Anandharamakrishnan and Ishwarya, 2015; Rajabi et al., 2015). Apart from spray drying, freeze drying and vacuum drying were also used in this study. Freeze drying uses the principle of freezing at low temperature and ice crystal sublimation so that bioactive components of VCO are not damaged (Liu et al., 2008). Vacuum drying uses a low-pressure drying technique (usually lower than the atmosphere pressure), in which the heat required for the drying process is lower and the drying process is faster than a typical dryer so that the bioactive components present in VCO can be maintained (Bazyma and Kutovoy, 2005; Parikh, 2015). These three drying techniques have different drying principles and have their own advantages and do not cause any damage to the bioactive components of VCO. Hence, these three drying techniques were selected for the drying process used to encapsulate VCO.

Thus, in this study Pickering emulsion mechanism was studied to determine the effect of Pickering emulsion with MCC and different drying techniques on the characteristics of VCO powder (measurement before drying: creaming index and emulsion droplet size, and measurement after drying: drying yield, color intensity, particle morphology, moisture content, microencapsulation efficiency, peroxide value, rehydration particle size, 
and dissolving time). For oxidation measurement, we chose peroxide value because oxidation reaction occurs in stages, where hydroperoxide is formed as a result of primary oxidation, while other techniques (anisidin and thiobarbituric acid [TBA] values) are used to measure the rancidity of the secondary or further oxidation. If the primary oxidation is bad, then it is possible that the results of the follow-up test would be bad as well. In addition, there is only a small amount of unsaturated fatty acid in VCO and because of limited time (30 days of storage), we only used peroxide value for oxidation measurement in this study.

\section{Materials and Methods}

\section{Materials}

Virgin Coconut Oil was obtained from Bali Coconut, a local market in Badung, North Kuta, Bali, Indonesia. Tween 80 was obtained from Croda, United Kingdom. Vivapur $^{\circledR}$ MCG 811 F MCC was obtained from JRS Pharma, Germany. Maltodextrin with a dextrose equivalent (DE) of 18 to 20 was obtained from Qin Huang Dao Lihua Starch Co. Ltd., Qin Huang Dao, China. n-Hexane, hydrochloric acid, ammonium thiocyanate, barium chloride dihydrate, iron (III) sulfate heptahydrate, iron (III) chloride, methanol, chloroform, isooctane and 2-propanol were pro-analyst chemicals and obtained from Supelco, Merck KgaA, Darmstadt, Germany.

\section{Preparation of emulsions}

The total solid was set at $30 \%(\mathrm{w} / \mathrm{w})$. The dispersion of maltodextrin and MCC in water was conducted according to the procedure described by Iijima and Takeo (2000) and Lim and Roos (2017) with some modifications. Maltodextrin with DE 18-20 was dissolved in distilled water at $55^{\circ} \mathrm{C}$ under heating and mechanical stirring by using a magnetic stirrer up to complete dissolution. The heating process was continued up to $70^{\circ} \mathrm{C}$. Then, MCC at $5 \%$ of VCO $(\mathrm{w} / \mathrm{w})$ was added gradually to the maltodextrin dispersion at $70^{\circ} \mathrm{C}$ with stirring using a magnetic stirrer up to complete dissolution. The MCC and maltodextrin dispersion was then cooled at room temperature to $45 \pm 3^{\circ} \mathrm{C}$ before the core material was added into it.

Emulsion was formed using a homogenization method according to the procedure described by Alcântara et al. (2019) and Xu et al. (2016) with some modifications. For the first emulsion treatment, Tween 80 at $1 \%$ of VCO $(\mathrm{w} / \mathrm{w})$ was mixed into distilled water at $25 \pm 3^{\circ} \mathrm{C}$ under mechanical stirring by using a magnetic stirrer until it was thoroughly mixed. Tween 80 at $1 \%$ of $\mathrm{VCO}(\mathrm{w} / \mathrm{w})$ was used in this study because good emulsion stability

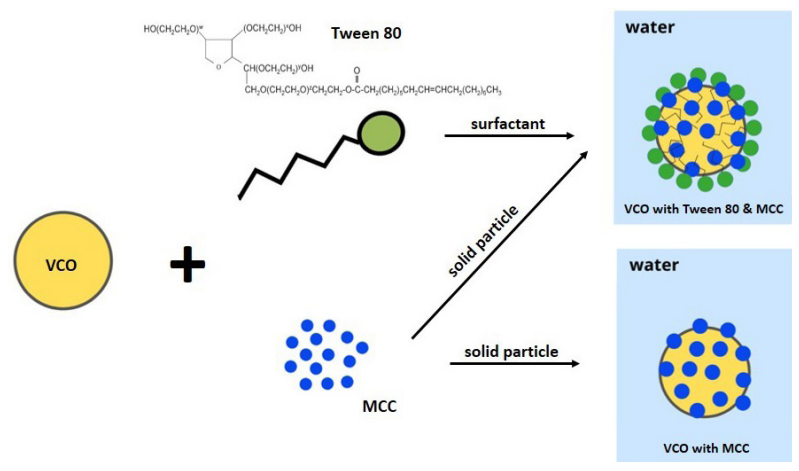

Figure 1. Schematic of VCO Pickering emulsion using the combination of Tween 80 and MCC, or MCC alone.

was obtained with this concentration based on the studies conducted by (Gomes et al. (2018) and Vicente et al. (2018). VCO at $40 \%$ of total solid (w/w) was added gradually to the mixture while stirring. According to conducted studies, the best microencapsulation efficiency is obtained when the concentration of oil is $30 \%$ of total solid $(w / w)$. The higher the concentration of oil, the lower the microencapsulation efficiency obtained (Alcântara et al., 2019). In this study, VCO at $40 \%$ of the total solid $(\mathrm{w} / \mathrm{w})$ was used with the help of Pickering emulsion as the novelty of the study (high oil concentration) because Pickering emulsion can increase emulsion stability for a longer period. The emulsion formed was then homogenized using a rotor-stator homogenizer (DLAB D500, China) (14,000 rpm, $5 \mathrm{~min})$. After this, the emulsion was poured gradually into the MCC and maltodextrin dispersion with mechanical stirring using a magnetic stirrer for 5 min followed by homogenization using the same homogenizer as used before. For the second emulsion treatment, VCO at $40 \%$ of the total solid (w/w) was added gradually to the MCC and maltodextrin dispersion with mechanical stirring by using a magnetic stirrer for 5 min followed by homogenization using the same homogenizer. The schematic of VCO Pickering emulsion using the combination of Tween 80 and MCC or using MCC alone is shown in Figure 1. It is observed in Figure 1, how the Tween 80 and MCC solid particles arrange themselves around the VCO droplet to enhance the stabilization of emulsion. The emulsion formed was kept in a glass beaker and stored overnight at room temperature $\left(25 \pm 3^{\circ} \mathrm{C}\right)$ before drying using the three techniques, spray drying, freeze drying and vacuum drying.

\section{Characterization of emulsions}

\section{Stability of emulsions}

The emulsion formed was immediately transferred to a test tube, closed and stored at $25 \pm 3^{\circ} \mathrm{C}$. Monitoring the stability of emulsion was carried out every week for 21 
days of storage right after its preparation. The height of the cream formed during storage was calculated using the creaming index (CI) as described by Equation (1) (Akhtar et al., 2014):

$$
\text { Creaming Index }=\frac{\mathrm{h}_{\mathrm{c}}}{\mathrm{h}_{\mathrm{t}}} \times 100 \% \text {, }
$$

where $h_{c}$ is the height of the cream $(\mathrm{cm})$ and $h_{t}$ is the height of the initial emulsion $(\mathrm{cm})$

\section{Droplet size of emulsions}

The droplet size of emulsion was determined by using the Laser Diffraction Particle Size Analyzer (LS 13 320, Beckman Coulter, United States). The measurement was carried out immediately after the emulsion was formed. The droplet size of the emulsion was expressed as the average size, and the calculation of polydispersity index (PDI) was exercised using Equation (2) (Hirschle et al., 2016):

$$
\mathrm{PDI}=\left(\frac{\sigma}{\mathrm{d}}\right)^{2}
$$

where $\sigma$ is the standard deviation of the particle size distribution $(\mu \mathrm{m})$, and $\mathrm{d}$ is the mean diameter of the particle $(\mu \mathrm{m})$.

\section{Spray drying process}

The emulsion was kept in a glass beaker and stored overnight at room temperature $\left(25 \pm 3^{\circ} \mathrm{C}\right)$; it was diluted with distilled water for as much as $50 \%$ of the total emulsion under stirring. The spray drying process was carried out in duplicate according to the procedure described by Sansone et al. (2011) with some modifications. A mini spray dryer (Buchi B-290, Flawil-Switzerland) was used for the spray drying process with inlet temperature adjusted at $150 \pm 3^{\circ} \mathrm{C}$, outlet temperature maintained at $70 \pm 3^{\circ} \mathrm{C}$, aspirator was set at $85 \%$, pump was set at $25 \%$, and the actual flow rate was maintained at $5 \mathrm{~mL} / \mathrm{min}$; the mixture was stirred gently while the feed was pumped to spray dryer to maintain homogeneity. The dried products were collected at collection chamber after the drying process was completed and sieved with a 40-mesh Tyler sieve to obtain a fine powder. All the spray-dried VCO powders were then kept at $4^{\circ} \mathrm{C}$ while waiting for 'day zero analysis', followed by storage tests at room temperature $\left(25 \pm 3^{\circ} \mathrm{C}\right)$.

\section{Freeze-drying process}

The freeze-drying process also was carried out in duplicate according to the procedure described by Anwar and Kunz (2011) with some modifications. The emulsion was kept in a glass beaker and stored overnight at room temperature $\left(25 \pm 3^{\circ} \mathrm{C}\right)$ and transferred to a plastic container for the initial freezing process at $-50^{\circ} \mathrm{C}$ for 24 h using a freezer (Thermo Scientific Hera Freeze Basic, United States). After the freezing process, a freeze dryer (Christ Alpha 1-4 LD Plus, Germany) was used for the freeze-drying process with temperature kept at $-50^{\circ} \mathrm{C}$ and pressure at $0.001 \mathrm{mbar}$ for $48 \mathrm{~h}$. The freeze-dried products were then milled in a mortar and pestle, and sieved with a 40-mesh Tyler sieve to obtain a fine powder. All freeze-dried VCO powders were kept at $4{ }^{\circ} \mathrm{C}$ while waiting for 'day zero analysis', followed by storage tests at room temperature $\left(25 \pm 3^{\circ} \mathrm{C}\right)$.

\section{Vacuum drying process}

The vacuum drying process also was carried out in duplicate according to the procedure described by Nurhadi and Roos (2017) with some modifications. The emulsion was kept in a glass beaker and stored overnight at room temperature $\left(25 \pm 3^{\circ} \mathrm{C}\right)$, and transferred to a silicone pan for drying using a vacuum oven (VWR Scientific, United States) with temperature and vacuum pressure set at $60^{\circ} \mathrm{C}$ and $25 \mathrm{inHg}$, respectively, for $6 \mathrm{~h}$. The vacuum-dried products were then milled in a mortar and pestle, and sieved with a 40-mesh Tyler sieve to obtain fine powder. All vacuum-dried VCO powders were then kept at $4{ }^{\circ} \mathrm{C}$ while waiting for 'day zero analysis', followed by storage tests at room temperature $\left(25 \pm 3^{\circ} \mathrm{C}\right)$.

\section{Powder analysis}

\section{Drying yield}

The drying yield (\%) is the ratio between the weight of the microcapsules obtained from the drying process $(\mathrm{g})$ and the total solid of emulsion which consists of VCO, Tween 80 , MCC, and maltodextrin (g). The drying yield was calculated using Equation (3) (Zhong et al., 2009):

$$
\text { Drying Yield }(\%)=\frac{M_{c}}{M_{t}} \times 100 \% \text {, }
$$

where $M_{C}$ is the weight of microcapsules obtained from the drying process $(\mathrm{g})$, and $\mathrm{M}_{t}$ is the total solid of the emulsion (g).

\section{Color analysis}

Color intensity was determined as described by Yam and Papadakis (2004) using a spectrophotometer (Konica Minolta CM-5 Spectrophotometer, Japan). This measurement was performed on day zero and every 15 days during 
the 30 -day storage at room temperature $\left(25 \pm 3^{\circ} \mathrm{C}\right)$. Before analysis, the instrument was calibrated using CM-A210 white calibration plate (Japan). Then the samples were captured and the results obtained were in the form of $L^{*}$ indicating the degree of lightness to darkness, $\mathrm{a}^{*}$ indicating the degree of redness to greenness and $b^{*}$ indicating the degree of yellowness to blueness. Hue angle $\left(\mathrm{H}^{*}\right)$, which indicates the color of VCO powder, was calculated using Equation (4), and chroma $\left(C^{*}\right)$ value, which indicates the saturation of VCO powder, was calculated using Equation (5) as described by Kuck and Noreña (2016):

$$
\begin{gathered}
\mathrm{H}^{*}=\tan ^{-1}\left(\frac{\mathrm{b}^{*}}{\mathrm{a}^{*}}\right), \\
\mathrm{C}^{*}=\left[\left(\mathrm{a}^{*}\right)^{2}+\left(\mathrm{b}^{*}\right)^{2}\right]^{1 / 2} .
\end{gathered}
$$

\section{Morphology of VCO powder}

The morphology of VCO powder was observed by using a scanning electron microscope (SEM), Tabletop Microscope Hitachi TM 3000 (Hitachi HighTechnologies Corporation, Tokyo, Japan). The sample was placed on a double-sided tape attached to the specimen stub. The specimen stub was then measured at appropriate height and put at a specimen stage. The observation mode was set, and the morphological structure of the particle was observed on computer screen.

\section{Moisture content}

The moisture content was measured using the gravimetric method according to official method of Association of Official Analytical Chemistry (AOAC, 2005b), with removal of water vapor by convective heat transfer using an oven at $105^{\circ} \mathrm{C}$ for $3 \mathrm{~h}$. The moisture content was measured in duplicate and the calculation of moisture content was performed on a wet basis using Equation (6):

$$
\text { Moisture Content }(\% \mathrm{wb})=\frac{\mathrm{w}_{1}-\left(\mathrm{w}_{2}-\mathrm{w}\right)}{\mathrm{w}_{1}} \times 100 \%
$$

where $\mathrm{w}$ is the constant weight of empty dish $(\mathrm{g}), \mathrm{w}_{1}$ is the weight of sample $(\mathrm{g})$ and $\mathrm{w}_{2}$ is the constant weight of dried sample + dish $(\mathrm{g})$.

\section{Microencapsulation efficiency}

Total oil $\left(\mathrm{O}_{\mathrm{T}}\right)$ is the overall oil in a microcapsule and comprises encapsulated oil $\left(\mathrm{O}_{\mathrm{E}}\right)$ and surface oil $\left(\mathrm{O}_{\mathrm{S}}\right)$. Total oil was determined by using the soxhlet extraction method according to the official method described by AOAC (2005a). Spray- and vacuum-dried powders were weighed as $2 \mathrm{~g}$ and hydrolyzed. Filter paper containing the oil was dried and put into hull to be extracted with soxhlet. Meanwhile, 2-g freeze-dried powder was weighed and put into hull and immediately extracted with soxhlet. The extraction process was carried out with a multi-heater extraction rack (Buchi B-810, Switzerland) for $3 \mathrm{~h}$ using $\mathrm{n}$-hexane solvent. Then the oil extract was dried in an oven at $105^{\circ} \mathrm{C}$ for $30 \mathrm{~min}$ to obtain a constant weight. The total oil was calculated using Equation (7):

$$
\mathrm{O}_{\mathrm{T}}(\%)=\frac{\mathrm{w}_{2}-\mathrm{w}_{1}}{\mathrm{w}} \times 100 \% \text {, }
$$

where $\mathrm{w}$ is the weight of the sample $(\mathrm{g}), \mathrm{w}_{1}$ is the constant weight of empty flask ( $g$ ) and $w_{2}$ is the constant weight of extract + flask $(\mathrm{g})$.

Surface oil $\left(\mathrm{O}_{\mathrm{s}}\right)$ or non-encapsulated oil is determined by the washing method using $\mathrm{n}$-hexane as described by Lim and Roos (2017). This measurement was conducted on day zero and every 15 days during the 30-day storage at room temperature $\left(25 \pm 3^{\circ} \mathrm{C}\right)$. The sample was weighed as $2 \mathrm{~g}$ on a funnel having a filter paper. The sample was washed for four times by using 10-mL $\mathrm{n}$-hexane for each wash. The beaker containing n-hexane and extracted surface oil was then left for two days for evaporation of $\mathrm{n}$-hexane. Then the beaker containing surface oil and remaining hexane was dried using an oven at $105^{\circ} \mathrm{C}$ for 30 min to obtain a constant weight. The calculation of surface oil was carried out by using Equation (8):

$$
\mathrm{O}_{\mathrm{S}}(\%)=\frac{\mathrm{w}_{2}-\mathrm{w}_{1}}{\mathrm{w}} \times 100 \%
$$

where $\mathrm{w}$ is the weight of the sample $(\mathrm{g}), \mathrm{w}_{1}$ is the constant weight of beaker $(\mathrm{g})$ and $\mathrm{w}_{2}$ is the constant weight of surface oil+beaker $(\mathrm{g})$.

The microencapsulation efficiency was calculated by comparing the encapsulated oil (total oil - surface oil) and the total oil from the sample as described by Anwar and Kunz (2011). The microencapsulation efficiency was calculated by using Equation (9):

$$
=\frac{\left(\mathrm{O}_{\mathrm{T}}-\mathrm{O}_{\mathrm{S}}\right)}{\mathrm{O}_{\mathrm{T}}} \times 100 \% \text {, }
$$$$
\text { Microencapsulation Efficiency (\%) }
$$

where $\mathrm{O}_{T}$ is the amount of total oil (\%) and $\mathrm{O}_{\mathrm{S}}$ is the amount of surface oil (\%).

\section{Peroxide value}

Peroxide indicates oil damage because of oxidation, which is characterized by the appearance of rancid odor in the products. The peroxide value of the sample was measured according to the official methods of International Organization for Standardization (ISO) and International 
Dairy Federation (IDF) (2006), and the oil extraction process from VCO powder was carried out as described by Partanen et al,(2008) with several modifications. This measurement was carried out on day zero and every 15 days during the 30-day storage at room temperature $\left(25 \pm 3^{\circ} \mathrm{C}\right)$. The sample was weighed as $0.5 \mathrm{~g}$ in a test tube and 0.5$\mathrm{mL}$ distilled water was added to it, and homogenized with a vortex mixer for $30 \mathrm{sec}$. Pipette $400-\mu \mathrm{L}$ sample solution into a microcentrifuge tube and $1.5-\mathrm{mL}$ isooctane:isopropanol (2:1 ratio) solution was added to it. The solution was centrifuged using a microcentrifuge (Thermo Scientific Sorvall Legend Micro 17R Centrifuge, United Kingdom) $\left(5,000 \mathrm{rpm}, 5 \mathrm{~min}, 25^{\circ} \mathrm{C}\right)$. The upper phase (supernatant) was separated for analysis. The extraction process was continued for up to three times of extraction using the same solvent and centrifuge. A $100-\mu \mathrm{L}$ aliquot of the extraction was moved to a test tube and $9.8 \mathrm{~mL}$ of chloroform:methanol (7:3 ratio) solution was added to it. For color formation, $50 \mu \mathrm{L}$ of $\mathrm{Fe}^{2+}$ solution (filtrate from the mixture of barium chloride solution $\left[0.2 \mathrm{~g} \mathrm{BaCl}_{2} \cdot 2 \mathrm{H}_{2} \mathrm{O}\right.$ was dissolved in $25-\mathrm{mL}$ distilled water] and iron (III) sulfate solution $\left[0.25 \mathrm{~g} \mathrm{FeSO}_{4} \cdot 7 \mathrm{H}_{2} \mathrm{O}\right.$ was dissolved in $25-\mathrm{mL}$ distilled water]) and $50 \mu \mathrm{L}$ of $30 \%$ ammonium thiocyanate solution ( $7.5 \mathrm{~g}$ dissolved in $25-\mathrm{mL}$ distilled water) were added to samples. The samples were homogenized using a vortex mixer and incubated in dark for $10 \mathrm{~min}$. The absorbance was measured by using a spectrophotometer (VIS7220G/UV-9200 Ray Leigh Spectrophotometer, Beijing, China) at $500 \mathrm{~nm}$, and the peroxide value was calculated by using a standard curve of $\mathrm{Fe}^{3+}(0-5 \mathrm{ppm})$.

\section{Particle size of rehydrated VCO powder}

The particle size of rehydrated VCO powder was determined using the laser diffraction particle size analyzer (LS 13 320, Beckman Coulter, United States). For rehydrated microcapsules, $50 \mathrm{~mL}$ of distilled water was added to $1 \mathrm{~g}$ of sample and stirred by using a magnetic stirrer at a speed of $892 \mathrm{rpm}$ with a $3-\mathrm{mm} \times 7-\mathrm{mm}$ magnetic bar at $25 \pm 3^{\circ} \mathrm{C}$ until dissolved completely. The measurement was carried out immediately after the rehydration process. The particle size of VCO powder was expressed as the average size, and the PDI was calculated using Equation (10) (Hirschle et al., 2016):

$$
\mathrm{PDI}=\left(\frac{\sigma}{\mathrm{d}}\right)^{2}
$$

where $\sigma$ is the standard deviation of particle size distribution $(\mu \mathrm{m})$, and $d$ is the mean diameter of particle $(\mu \mathrm{m})$.

\section{Dissolving time}

Dissolving time was measured as described by Tinay and Ismail (1985). Distilled water, $50 \mathrm{~mL}$, was added to $1 \mathrm{~g}$ of sample and stirred using a magnetic stirrer at a speed of $892 \mathrm{rpm}$ with a $3-\mathrm{mm} \times 7-\mathrm{mm}$ magnetic bar at $25 \pm 3^{\circ} \mathrm{C}$. The time taken for all solid particles to dissolve completely in the solvent was recorded as the dissolving time.

\section{Results and Discussion}

\section{Characterization of emulsions}

\section{Creaming index}

Emulsion instability usually occurs if the emulsion is stored for a long period. The major cause of emulsion instability is creaming due to gravitational separation, resulting in the separation of emulsion system into two layers. However, the Pickering emulsion system is more stable because it requires more energy to remove solid particles from the emulsion system (Ahsan et al., 2020). As observed in Table 1, all VCO emulsions did not depict creaming or other types of instability (creaming index $=0 \%$ ) up to 21 days of storage. This means that Pickering emulsion with MCC, with or without Tween 80 can maintain the stability of emulsion system for up to 21 days. In the mechanism of Pickering emulsion, MCC is absorbed onto the $\mathrm{VCO}$ droplet surface, thus covering the droplet surface by forming a thick layer which acts as a barrier to prevent flocculation between VCO droplets (Xu et al., 2016). Apart from this, addition of MCC in high concentrations also result in the presence of MCC in continuous phase, which increases the viscosity to make a gel-like continuous phase (Wei et al., 2019; Zhang et al., 2017a, 2017b). This happened in this study because the MCC used was

Table 1. The characteristics of VCO Pickering emulsion with MCC.

\begin{tabular}{|c|c|c|c|c|c|c|}
\hline \multirow[b]{2}{*}{ Sample } & \multicolumn{4}{|c|}{ Creaming index (\%) } & \multirow[b]{2}{*}{ Droplet size $(\mu \mathrm{m})$} & \multirow[b]{2}{*}{ PDI } \\
\hline & Day 0 & Day 7 & Day 14 & Day 21 & & \\
\hline VCO emulsion with Tween 80 and MCC & 0 & 0 & 0 & 0 & $1.3620 \pm 0.0193$ & $0.2024 \pm 0.0103$ \\
\hline VCO emulsion with MCC & 0 & 0 & 0 & 0 & $1.4678 \pm 0.0163$ & $0.1691 \pm 0.0119$ \\
\hline
\end{tabular}


a colloidal type Vivapur ${ }^{\circledR}$ MCG 811 F MCC containing 11.30-18.80\% carboxymethyl cellulose (CMC). Presence of $\mathrm{CMC}$ made droplets in the continuous phase unable to move freely because of the formation of a three-dimensional (3D) network between MCC and water that bound VCO droplets tightly to prevent phase separation (Ahsan et al., 2020; Xu et al., 2016). This mechanism was in accordance with the terminal velocity equation of Stokes' Law because emulsion stability is directly proportional to viscosity (McClements, 2005). Similar results were observed by $\mathrm{Xu}$ et al. (2016), where the stability of emulsion system made with low molecular surfactants was increased by MCC adsorption on oil droplet surface. Kargar et al. (2012) and Xu et al. (2016) also had a similar result, where the addition of MCC to an o/w emulsion without surfactant produced a good emulsion stability.

The VCO emulsion prepared with MCC alone had a higher viscosity than the VCO emulsion prepared with Tween 80 and MCC. The use of surfactant (Tween 80) resulted in the $-\mathrm{OH}$ group from Tween 80 binding to the $-\mathrm{OH}$ group from water so that it can reduce interaction between MCC particles and water to form a 3D network, resulting in decreased emulsion viscosity (Raman and Aichele, 2020; Vashisth et al., 2010). Although the viscosity was different, both emulsions had a good stability of up to 21 days. Therefore, Pickering emulsion with MCC, with or without Tween 80 , could maintain the stability of VCO emulsion system for a longer period.

\section{Droplet size of emulsions}

The stability of an emulsion system also depends on the size of droplet, where the size of droplet is influenced by the homogenization process (time and speed), and the type and concentration of emulsifier (Hadnadev et al., 2013). As observed in Table 1, the VCO emulsion with Tween 80 and MCC had a smaller droplet size. This phenomenon occurred due to the process by which surfactant and solid particles reached the oil-water interface during the emulsification process. At the beginning of the process, the droplet size would be reduced drastically so that the interface area in the emulsion system increased rapidly. The low molecular surfactant (Tween 80) would gather quickly at the oil-water interface and reduced its surface tension, thereby allowing a more efficient breakdown of oil droplets during the emulsification process, resulting in smaller droplet size of emulsion. Besides, the presence of this surfactant could temporarily stabilize the emulsion system (Pichot et al., 2010; Raman and Aichele, 2020). Furthermore, the added solid particles (MCC) would coat all the available oil-water interfaces and significantly reduce the coalescence. This mechanism of stabilization of mixed emulsifier system produced smaller emulsion droplets than those produced by using surfactants or solid particles only. This has also been proved by Pichot et al. (2010) and Raman and Aichele (2020).

The PDI value demonstrates an overview of the distribution data of particles of different sizes in an emulsion system. PDI is a scale and has no dimensions, with the PDI value are ranging from $<0.05$ (rarely found) to a maximum of 1.0 (Vicente et al., 2018). According to Das and Chaudhury (2011), a PDI value of $>0.30$ indicates that the particles are no longer homogeneous. According to McClements (2005), a PDI value of $>0.50$ indicates a very heterogeneous and wide distribution of particle size or very polydispersity, and a PDI value of 1.0 indicates that the sample has the possibility of containing large particles or aggregates which would eventually form a sediment (Vicente et al., 2018). As observed in Table 1, both emulsion systems had a PDI $<0.30$, which means they had a homogeneous particle size distribution.

\section{Powder analysis}

\section{Drying yield}

The VCO powder has different drying yield values depending on the microencapsulation process and coating materials. Low drying yield can occur during the drying process because of stickiness in drying chamber, milling and sieving tools, or spill during the drying, milling and sieving processes (Nurhadi et al., 2012). As observed in Table 2, spray drying resulted in the lowest drying yield followed by vacuum drying, and the highest drying yield was obtained by freeze drying with the same ratio of oil and coating materials.

Spray drying had the lowest drying yield because of high probability of microencapsules sticking to the drying chamber (Yanuwar et al., 2007). Furthermore, the relatively low inlet temperature of spray drying used in this study $\left(150^{\circ} \mathrm{C}\right)$ with the aim of maintaining its bioactive components might have contributed to low drying yield (Tonon et al., 2008). Vacuum drying had a slightly higher drying yield than spray drying. This was because the vacuum process absorbed water of the sample so that the sample would be sprayed in the oven, resulting in a low drying yield. Meanwhile, freeze drying had the highest drying yield because almost all solids of the freeze-dried emulsion could be used. Freeze-drying process is through water freezing and ice sublimation so that it never causes any product loss. Similar results were observed by Román et al. (2020), as the drying yield of rice bran oil powder produced from freeze-drying technique was higher than spray drying technique (96.9\% vs. 50.8\%). From the viewpoint of different emulsion treatments, the drying yield obtained from VCO emulsion with Tween 80 and MCC 
Table 2. Characteristics of VCO powder from Pickering emulsion with MCC and different drying techniques.

\begin{tabular}{lccccc} 
Sample & Drying yield (\%) & Moisture content $(\%$ wb) & Rehydrated particle size $(\mu \mathrm{m})$ & PDI & Dissolving time $(\mathbf{s e c})$ \\
\hline A & $44.98 \pm 6.78 \%$ & $3.83 \pm 0.01 \%$ & $1.5017 \pm 0.0099$ & $0.1358 \pm 0.0029$ & $108.50 \pm 16.26$ \\
B & $94.03 \pm 2.83 \%$ & $3.51 \pm 0.47 \%$ & $1.4820 \pm 0.0139$ & $0.1423 \pm 0.0040$ & $78.75 \pm 2.47$ \\
C & $48.98 \pm 4.11 \%$ & $2.19 \pm 0.56 \%$ & $1.5203 \pm 0.0155$ & $0.1339 \pm 0.0088$ & $156.50 \pm 3.54$ \\
D & $53.86 \pm 4.98 \%$ & $3.49 \pm 0.24 \%$ & $1.5460 \pm 0.0104$ & $0.1153 \pm 0.0017$ & $188.25 \pm 3.18$ \\
E & $96.43 \pm 1.71 \%$ & $4.74 \pm 1.38 \%$ & $1.5197 \pm 0.0025$ & $0.1304 \pm 0.0019$ & $101.50 \pm 5.66$ \\
F & $55.66 \pm 6.25 \%$ & $3.42 \pm 1.52 \%$ & $1.5493 \pm 0.0064$ & $0.1106 \pm 0.0013$ & $258.20 \pm 12.73$ \\
\hline
\end{tabular}

Values are mean \pm SD of duplicate determination.

PDI: polydispersity index; $w b=$ wet basis.

$\mathrm{A}=\mathrm{VCO}+$ Tween $80+\mathrm{MCC}$ by spray drying; $\mathrm{B}=\mathrm{VCO}+$ Tween $80+\mathrm{MCC}$ by freeze drying; $\mathrm{C}=\mathrm{VCO}+$ Tween $80+\mathrm{MCC}$ by vacuum drying; $\mathrm{D}=\mathrm{VCO}+\mathrm{MCC}$ by spray drying; $\mathrm{E}=\mathrm{VCO}+\mathrm{MCC}$ by freeze drying; $\mathrm{F}=\mathrm{VCO}+\mathrm{MCC}$ by vacuum drying.

Table 3. The $L^{*}, a^{*}, b^{*}$, Hue and Chroma values of VCO powder from Pickering emulsion with MCC and different drying techniques during storage.

\begin{tabular}{lllllll} 
Sample & & $\mathbf{L}^{*}$ & $\mathbf{a}^{*}$ & $\mathbf{b}^{*}$ & Hue & Chroma \\
\hline A & Day 0 & $92.46 \pm 1.17$ & $-0.30 \pm 0.10$ & $3.29 \pm 1.13$ & $95.28 \pm 0.15$ & $3.30 \pm 1.13$ \\
& Day 15 & $91.78 \pm 1.39$ & $-0.26 \pm 0.02$ & $2.91 \pm 1.07$ & $95.40 \pm 1.56$ & $2.92 \pm 1.07$ \\
B & Day 30 & $91.85 \pm 1.75$ & $-0.24 \pm 0.04$ & $3.01 \pm 0.56$ & $94.56 \pm 0.04$ & $3.02 \pm 0.56$ \\
& Day 0 & $93.32 \pm 0.17$ & $-0.14 \pm 0.09$ & $1.83 \pm 0.47$ & $94.96 \pm 4.02$ & $1.84 \pm 0.46$ \\
& Day 15 & $93.83 \pm 0.34$ & $-0.17 \pm 0.09$ & $2.01 \pm 0.17$ & $94.82 \pm 3.00$ & $2.02 \pm 0.16$ \\
C & Day 30 & $93.72 \pm 0.42$ & $-0.16 \pm 0.10$ & $2.03 \pm 0.02$ & $94.37 \pm 2.81$ & $2.04 \pm 0.01$ \\
& Day 0 & $79.64 \pm 0.22$ & $-1.45 \pm 0.44$ & $10.21 \pm 3.26$ & $98.12 \pm 0.13$ & $10.31 \pm 3.29$ \\
D & Day 15 & $80.22 \pm 0.22$ & $-1.21 \pm 0.39$ & $8.31 \pm 2.36$ & $98.23 \pm 0.30$ & $8.39 \pm 2.39$ \\
& Day 30 & $79.14 \pm 0.70$ & $-1.24 \pm 0.36$ & $2.33 \pm 0.40$ & $117.78 \pm 2.91$ & $2.64 \pm 0.53$ \\
& Day 0 & $95.17 \pm 0.46$ & $-0.12 \pm 0.07$ & $2.48 \pm 0.56$ & $92.91 \pm 2.28$ & $2.48 \pm 0.55$ \\
E & Day 15 & $94.60 \pm 0.15$ & $-0.09 \pm 0.09$ & $2.74 \pm 0.49$ & $92.09 \pm 2.30$ & $2.74 \pm 0.49$ \\
& Day 30 & $94.22 \pm 0.11$ & $-0.09 \pm 0.08$ & $2.62 \pm 0.45$ & $92.16 \pm 2.22$ & $2.62 \pm 0.44$ \\
& Day 0 & $93.54 \pm 0.26$ & $-0.18 \pm 0.03$ & $1.82 \pm 0.15$ & $95.63 \pm 1.45$ & $1.83 \pm 0.14$ \\
F & Day 15 & $93.19 \pm 0.29$ & $-0.18 \pm 0.04$ & $1.78 \pm 0.15$ & $95.70 \pm 1.84$ & $1.79 \pm 0.15$ \\
& Day 30 & $92.84 \pm 0.17$ & $-0.18 \pm 0.04$ & $1.66 \pm 0.01$ & $96.12 \pm 1.31$ & $1.66 \pm 0.01$ \\
& Day 0 & $86.77 \pm 1.76$ & $-0.84 \pm 0.47$ & $7.49 \pm 1.26$ & $96.18 \pm 2.50$ & $7.54 \pm 1.30$
\end{tabular}

*Values are mean $\pm S D$ of duplicate determination.

$\mathrm{A}=\mathrm{VCO}+$ Tween $80+\mathrm{MCC}$ by spray drying; $\mathrm{B}=\mathrm{VCO}+$ Tween $80+\mathrm{MCC}$ by freeze drying; $\mathrm{C}=\mathrm{VCO}+$ Tween $80+\mathrm{MCC}$ by vacuum drying; $\mathrm{D}=\mathrm{VCO}+\mathrm{MCC}$ by spray drying; $\mathrm{E}=\mathrm{VCO}+\mathrm{MCC}$ by freeze drying; $\mathrm{F}=\mathrm{VCO}+\mathrm{MCC}$ by vacuum drying.

was lower than that obtained from VCO emulsion only with MCC. Low viscosity from the emulsion system caused low drying yield, and vice versa (Sarungallo et al., 2019). This result was in accordance with the literature, where the emulsion system with Tween 80 and MCC had a lower viscosity, resulting in a lower drying yield.

\section{Color analysis}

According to Table 3, the high degrees of lightness to darkness ( $\mathrm{L}^{*}$ value) in VCO powder resulted from spray and freeze drying. However, lower $L^{*}$ value was obtained from vacuum-dried powder. Similar results were observed by Horszwald et al. (2013) and Michalska and Lech (2018). The long-term use of heat in the vacuum drying process allowed the product to be oxidized and could even be burnt due to caramelization reaction (nonenzymatic browning). Meanwhile, the spray drying process used high temperatures in a very short time, so it did not significantly affect the characteristics of $\mathrm{VCO}$ powder. Similarly, the freeze-drying process also did not use heat so that the original color of the product could be maintained. However, all VCO powders obtained from all 
drying techniques had white to light cream color, which met the commercial standards of consumer acceptance based on SNI 4444:2009 (Badan Standarisasi Nasional, 2009).

All samples of VCO powder produced by different drying techniques had a slightly greenish color with different degrees of redness to greenness ( $\mathrm{a}^{*}$ value) but still close to zero, which is neutral, except for vacuum-dried VCO powder with a more greenish color. The lengthy process of vacuum drying resulted in the formation of green pigments from colorless precursors present in VCO. The pigments were not from the chlorophyll group, and as described by Joslyn and Sano (1956), the specific compound responsible for the green pigment formed in garlic maceration tissue was not yet known.

All VCO powders also had a positive degrees of yellowness to blueness ( $\mathrm{b}^{*}$ value), which means that powders tended to have a yellowish color. Vacuum-dried VCO powder had the highest $b^{*}$ value, because of Tween 80 and MCC or MCC alone. These results were in accordance with the results obtained by Nurhadi et al. (2012), where the vacuum-dried honey powder had the highest $b^{*}$ value because of the long-term heating effect of drying process. After 30 days of storage, there was a decrease in the $b^{*}$ value of vacuum-dried VCO powder, especially in sample $C$, caused by a greenish pigment formed due to lengthy vacuum drying process. During storage, the greenish pigment turned brown due to exposure to oxygen and would gradually turn yellowish and finally to a light cream color, as described by Joslyn and Sano (1956).

The VCO powder obtained from Pickering emulsion with MCC and different drying techniques demonstrated no significant difference in lightness after 30 days of storage. In addition, $\mathrm{VCO}$ powder obtained from an emulsion using Tween 80 and MCC also had lower $L^{*}$ and $a^{*}$ values but a higher $b^{*}$ value because of the yellowish color of Tween 80 that affected the lightness and the color of VCO powder.

The color or shade (hue angle value) of VCO powders ranged from 92.09 to 98.23 , confirming that the sample was tended yellow in hue, with the highest hue angle value found in sample $\mathrm{C}$ (vacuum-dried VCO powder from the emulsion using Tween 80 and MCC). All VCO powders had stable hue angle values, except sample $C$, and increased up to $117.78 \pm 2.91$ on the 30th day of storage because of decrease in $b^{*}$ value.

The spray- and freeze-dried VCO powders had a low saturation (chroma value) compared to vacuum-dried VCO powder, especially sample $C$, and were stable for up to 30 days of storage. Meanwhile, the chroma value of sample $\mathrm{C}$ decreased steadily until the 30th day of storage, resulting in a more faded color.

Overall, VCO powders obtained from all drying techniques had a white to slightly yellowish hue. However, VCO powder obtained from spray drying (samples A and D) and freeze drying (samples B and E) had a slightly yellowish and a little bit of greenish in white hue but still having a bright coloration. Meanwhile, the VCO powder obtained from vacuum drying tended to be more yellowish and greenish than the powders obtained from other two drying techniques because of the long vacuum drying process.

\section{Morphology of VCO powder}

As observed in Figure 2, the spray-dried VCO powders (samples A and D) had a specific particle morphology, which was spherical in shape with a smooth surface
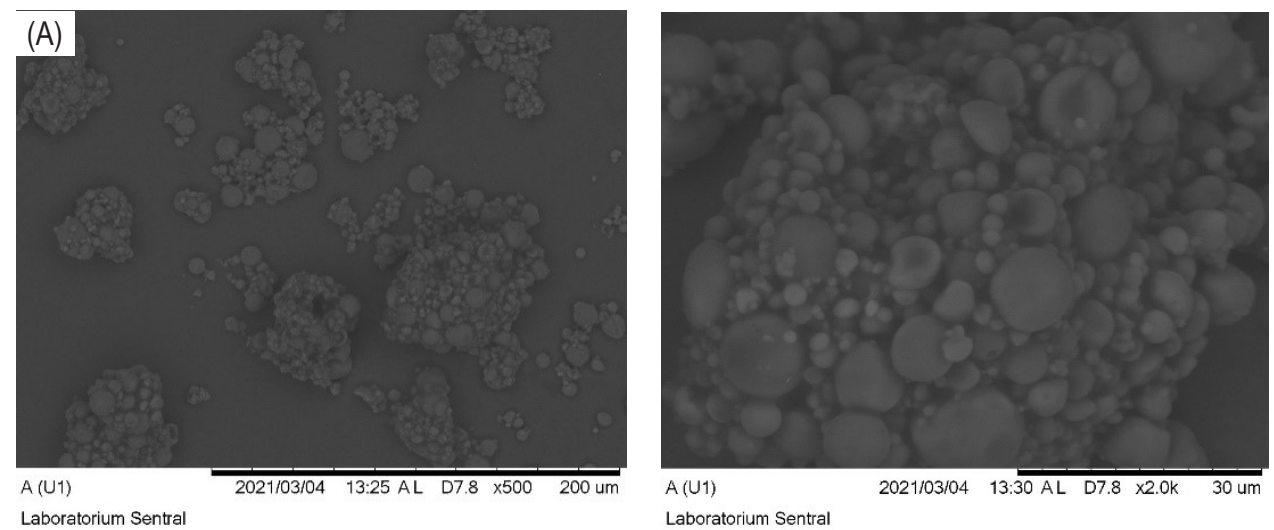

Figure 2. Morphology of VCO powder from Pickering emulsion with MCC and different drying techniques. $A=V C O+T w e e n$ $80+$ MCC by spray drying; $B=V C O+$ Tween $80+$ MCC by freeze drying; $C=V C O+$ Tween $80+$ MCC by vacuum drying; $\mathrm{D}=\mathrm{VCO}+\mathrm{MCC}$ by spray drying; $\mathrm{E}=\mathrm{VCO}+\mathrm{MCC}$ by freeze drying; $\mathrm{F}=\mathrm{VCO}+\mathrm{MCC}$ by vacuum drying. 
(B)

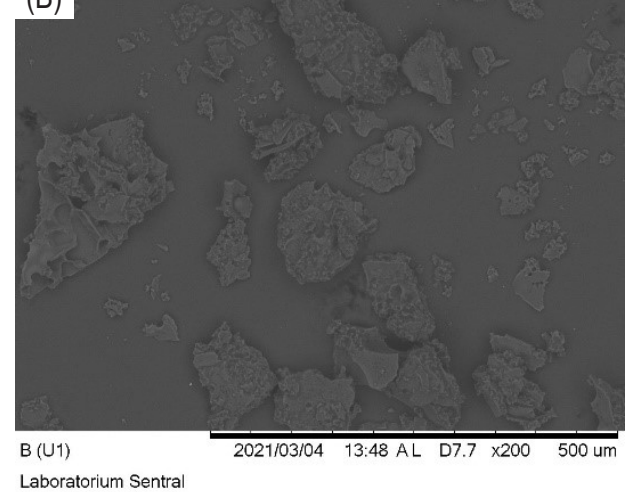

(C)

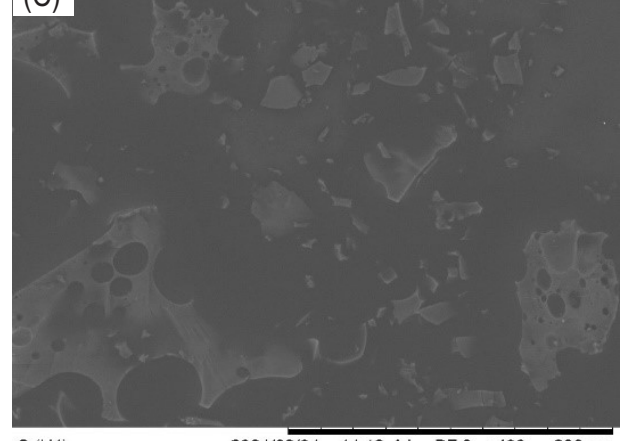

$$
\mathrm{C}(\mathrm{U} 1)
$$

$2 0 2 1 / 0 3 \longdiv { 1 0 4 } \quad 1 4: 18$ AL $\quad$ D7.9 $\times 400 \quad 200$ um Laboratorium Sentral

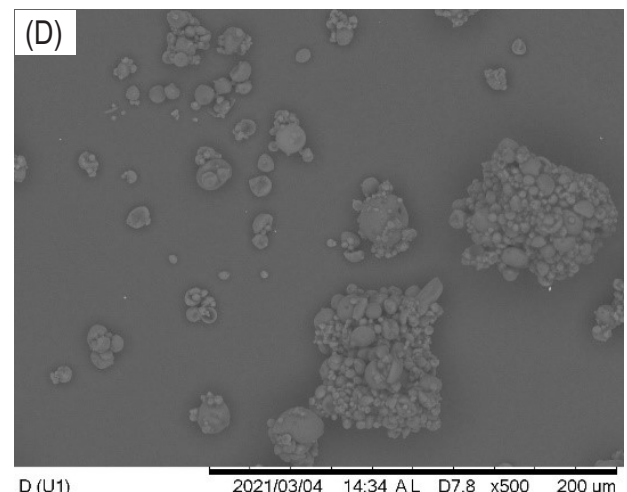
Laboratorium Sentral

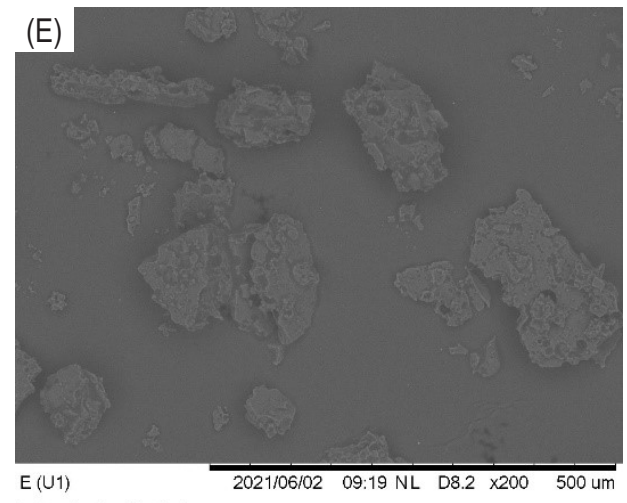

Laboratorium Sentral

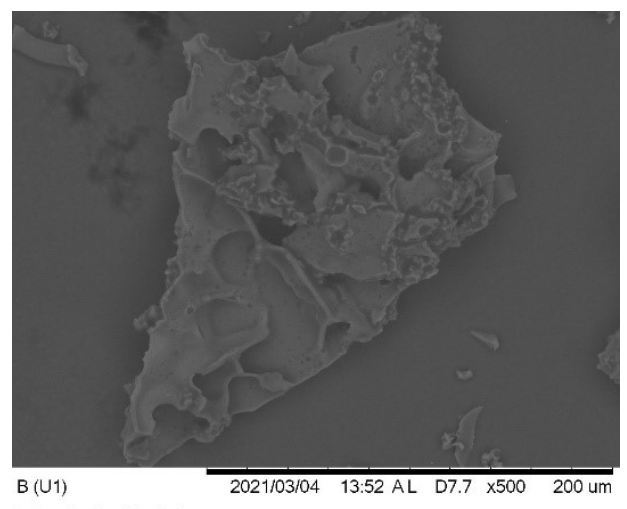

Laboratorium Sentral

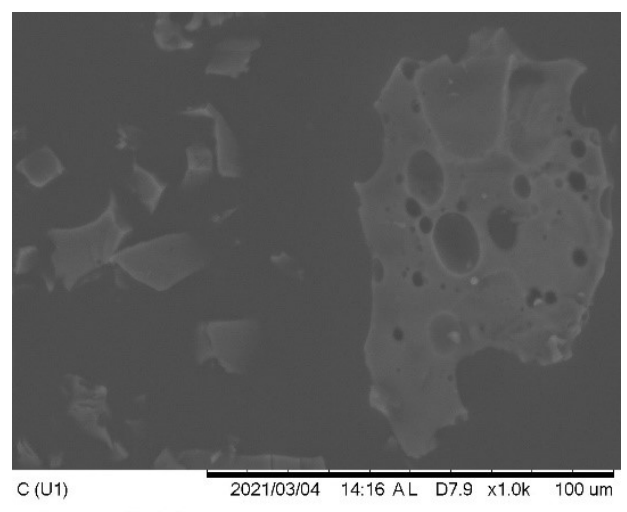

Laboratorium Sentral
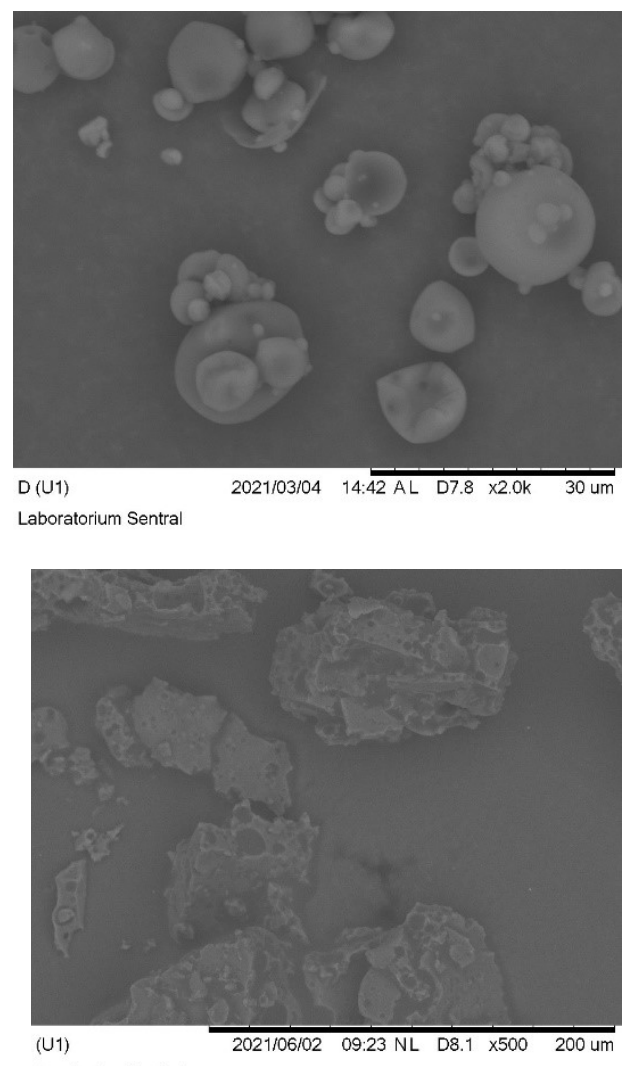

aboratorium Sentral

Figure 2. (Continued) 


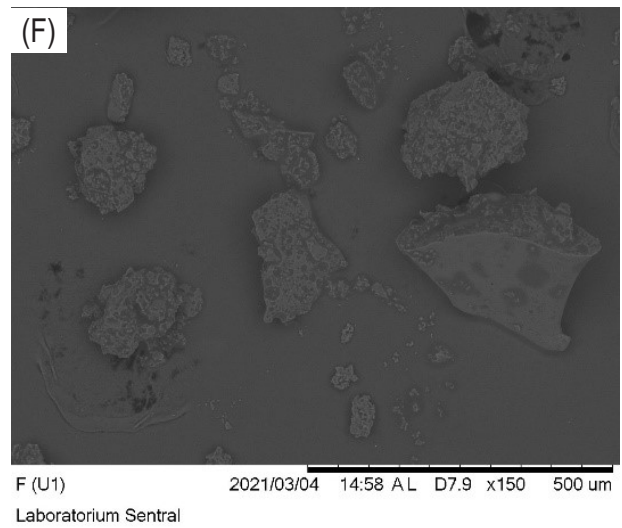

Figure 2. (Continued)

and no pores but some dents caused by rapid water loss during the initial drying process (Ré, 1998; Román et al., 2020; Wilkowska et al., 2017). The smooth surface of spray-dried particles was caused by the atomization process of spray drying (Pasrija et al., 2015). Similar results have been reported by several studies using different coating materials, such as modified starch (Melgosa et al., 2019), pea protein (Moreno et al., 2016), various biopolymers (Gallardo et al., 2013), a combination of maltodextrin and pea protein isolate (Román et al., 2020) or a combination of maltodextrin and soy protein isolate (Carneiro et al., 2013). In addition, there were also small particles adhered to the surface of spray-dried particles that could be the oil non-capsulized by the matrix, thus inducing other particles to stick to the surface and form a cluster (Román et al., 2020). These spherical-shaped particles were perfect for microencapsulation with bioactive components perfectly protected inside the coating agent. Likewise, spray-dried VCO powder had a more regular and uniform shape and size so that the solubility would be more uniform.

Samples B and E, which were freeze-dried VCO powders, had a wrinkled sponge-like morphology with an irregular surface and nonuniform shape, and very light and high porosity. Therefore, these particles had a large surface area. The presence of pores and wrinkles in the particles because of the usage of MCC fastened water removal from the material (Dhar et al., 2012) as well as the fast sublimation process of ice crystals on the matrix during freeze drying, resulting in the formation of pores which previously were ice crystals (Smrdel et al., 2008). Similar particle morphology has been reported by other studies using different coating materials, such as sodium alginate in anthocyanin extract microcapsules (Zhang et al., 2020), a combination of various polymers in fish oil microcapsules (Anwar and Kunz, 2011), and a combination of maltodextrin and pectin in the microcapsules of Moringa stenopetala leaf extract (Dadi et al., 2020).

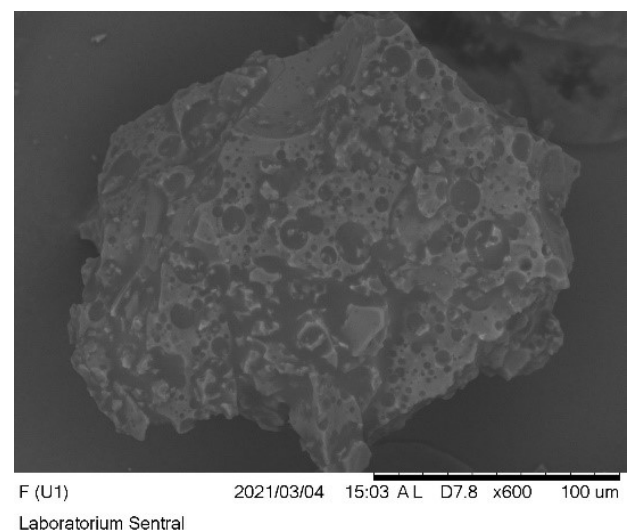

Laboratorium Sentra
High porosity of this freeze-dried VCO powder made it suitable for instant powder drink because it caused rapid dissolution in solvent, but the dissolution was just not uniform because of the nonuniform shape compared to spherical-shaped particles' dissolution.

Samples C and F, which were vacuum-dried VCO powders, had an angular and nonuniform morphology with large cavities on their surfaces. Similar result was observed by Mutlu et al. (2020). The presence of cavities in the particles was caused by the suction/vacuum process of water vapor from the heated material to produce dry products with large hollows (Reis, 2014). This particle morphology was almost the same as that of freeze-dried particles but not porous and also had a high surface oil, so it was very oily resulting in low wettability and solubility, making it unsuitable for instant powder drinks.

\section{Moisture content}

The VCO powders had different moisture contents depending on the drying techniques and ranged from $2.19 \%$ to $4.74 \%$ (Table 2). The moisture content obtained was under $5 \%$, which means all of the VCO powders were still accepted in the food industry (Díaz et al., 2020). The freeze-dried VCO powder from emulsion with only MCC had the highest moisture content because of its porous structure, so it was more hygroscopic with a higher adsorption capacity than other dried samples (Gong et al., 2007). The freeze-drying process that used temperatures lower than $-40^{\circ} \mathrm{C}$ also resulted in the obstruction of mass transfer and sublimation process because of rapid freezing of outer layer pores, thereby increasing the retention of moisture in microcapsules. Similar results were observed by Kuck and Noreña (2016), where the grape skin phenolic extract powder produced by freeze drying had a higher water content than spray drying. 
The vacuum-dried VCO powder from emulsion using Tween 80 and MCC had the lowest moisture content caused by vacuum conditions of drying that reduced the heat required to evaporate water so that water evaporation occurred quickly at low pressure (Piwińska et al., 2015). Similar results of the moisture content were also obtained by Nurhadi et al. (2012), where the vacuumdried honey powder had a lower moisture content than spray-dried honey powder.

VCO powders obtained from emulsions with MCC only (samples D and F) had a higher moisture content. This was due to the higher viscosity of emulsion, resulting in decreased water diffusion during the drying process because the total solid concentration was more than 20\% (Frascareli et al., 2012). In addition, use of Tween 80 also produced VCO powder with a low moisture content because of foam formation in the emulsion system (Mayasari et al., 2019). The foam layer dried faster than the liquid under the same drying conditions. As a result, the drying process was completed quickly and produced microcapsules with a lower moisture content (Kamsiati, 2006).

\section{Microencapsulation efficiency}

Microencapsulation efficiency is defined as the ratio between encapsulated oil and total oil contained in particles (Tonon et al., 2012). The microencapsulation efficiency depends on several factors, such as the ratio of core material to coating material, chemical properties, effect of material interactions, and the microencapsulation techniques (Dadi et al., 2020).

In Figure 3, all VCO powders had a low microencapsulation efficiency, which is $<50 \%$. The low microencapsulation efficiency is caused by the high concentration of oil (40\%), so there would be a lack of coating material to encapsulate oil, thus resulting in high surface oil and low encapsulated oil (Frascareli et al., 2012). Similar results were also demonstrated in the study conducted by McNamee et al. (1998) on encapsulation of soybean oil with gum arabic, where the encapsulation efficiency was reduced from $100 \%$ to $48 \%$ with oil and gum arabic ratio increasing from 0.25 to 5.00. Several other studies have also demonstrated similar results (Ahn et al., 2008; Alcântara et al., 2019).

The freeze-dried VCO powder from both emulsion treatments had the lowest microencapsulation efficiency because of high surface oil on particles. The freezing process induced demulsification in the emulsion system because some droplets froze first and the volume of frozen droplets increased, resulting in collisions between droplets, thus damaging water and emulsifier layers that covered the droplets. Many droplets froze together to form larger ice domains due to coalescence, and also some droplets froze because of partial contact with other ice, which is commonly referred to as 'partial coalescence.' The coalescence of particles produced an even larger particle, which at a certain particle size triggered phase separation resulting in high non-encapsulated oil

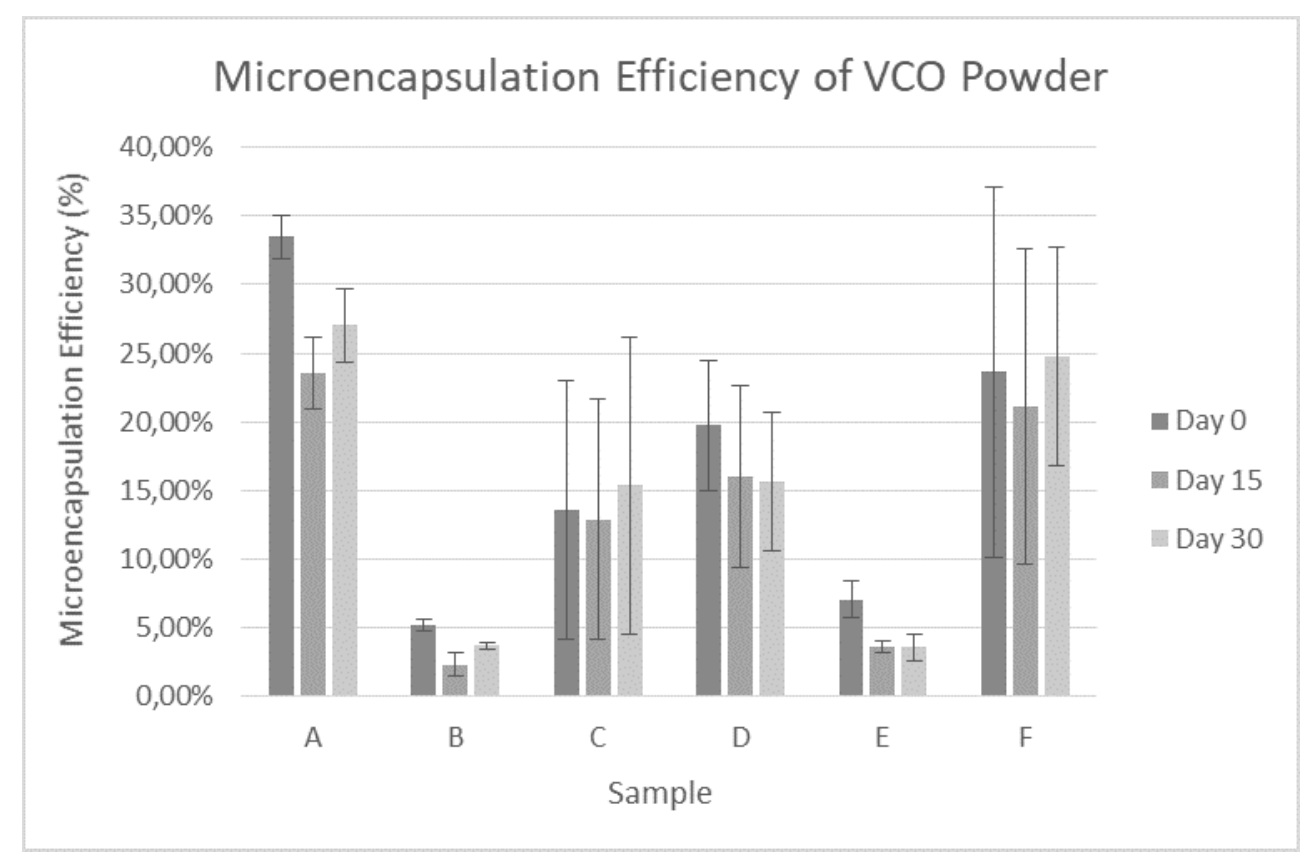

Figure 3. Microencapsulation efficiency of VCO powder from Pickering emulsion with MCC and different drying techniques during storage. $\mathrm{A}=\mathrm{VCO}+$ Tween $80+\mathrm{MCC}$ by spray drying; $\mathrm{B}=\mathrm{VCO}+$ Tween $80+\mathrm{MCC}$ by freeze drying; $\mathrm{C}=\mathrm{VCO}+\mathrm{Tween}$ $80+M C C$ by vacuum drying; $D=V C O+M C C$ by spray drying; $E=V C O+M C C$ by freeze drying; $F=V C O+M C C$ by vacuum drying 
in freeze-dried samples (Lin et al., 2007). Similar results were obtained by Anwar and Kunz (2011) in microencapsulationof fish oil using freeze drying.

The highest microencapsulation efficiency was obtained by spray drying in the emulsion using Tween 80 and MCC (sample A), with a microencapsulation efficiency of $33.49 \pm 1.59 \%$. As observed in Figure 2, particles produced by the spray-drying technique had no cracks and pores in their microstructure, so they would have a good microencapsulation efficiency (Pereira et al., 2019). Besides this, using Tween 80 in the emulsion system resulted in a smaller emulsion droplet size, which would result in a higher microencapsulation efficiency. Similar results were observed by Soottitantawat et al. (2005), and also supported by Shamaei et al. (2017), where there was no correlation between microencapsulation efficiency and microparticle size (or emulsion droplet size).

In addition to spray drying, freeze- and vacuum-dried VCO powders obtained from the emulsion with MCC only had a higher microencapsulation efficiency. This may be affected by the viscosity of emulsion, where using Tween 80 resulted in a lower emulsion viscosity, but the emulsion with MCC only had a higher viscosity. Thus, a stronger matrix was formed in the emulsion using MCC only that helped to prevent the diffusion/migration of oil from matrix to produce microcapsules with higher encapsulated oil (Sarungallo et al., 2019).
The microencapsulation efficiency of VCO powder demonstrated decrease on the 15th and 30th day of storage, which means that more oil was diffused from matrix, resulting in high surface oil. Similar results were observed by Esparza et al. (2020), where the microencapsulation efficiency of hempseed oil powder stabilized with nanocrystalline cellulose Pickering emulsion decreased after 30 days of storage.

\section{Peroxide value}

Peroxide is an indicator to determine the level of oxidation of fats and oil products. The peroxide value of all VCO powders depicted a higher value compared to the characterization result of $\mathrm{VCO}$, which was only 0.052 $\mathrm{mEq} \mathrm{O}_{2} / \mathrm{kg}$. This indicated that exposure to light, oxygen and heat during the microencapsulation process could facilitate oxidation (Mubarak, 2017). However, increase in the peroxide value was still below the maximum limit of the quality requirements of VCO peroxide value, which is $2.0 \mathrm{mEq} \mathrm{O} / 2 / \mathrm{kg}$ based on SNI 01-7381-2008 (Badan Standardisasi Nasional, 2008), which established that VCO powder was still safe for consumption. A slight increase in the peroxide value of VCO powder was due to a small amount of unsaturated fatty acids (about 10\%) that we discovered in VCO, which could be oxidized easily.

In Figure 4, the spray-dried VCO powder (samples A and D) demonstrated the highest peroxide value, and the

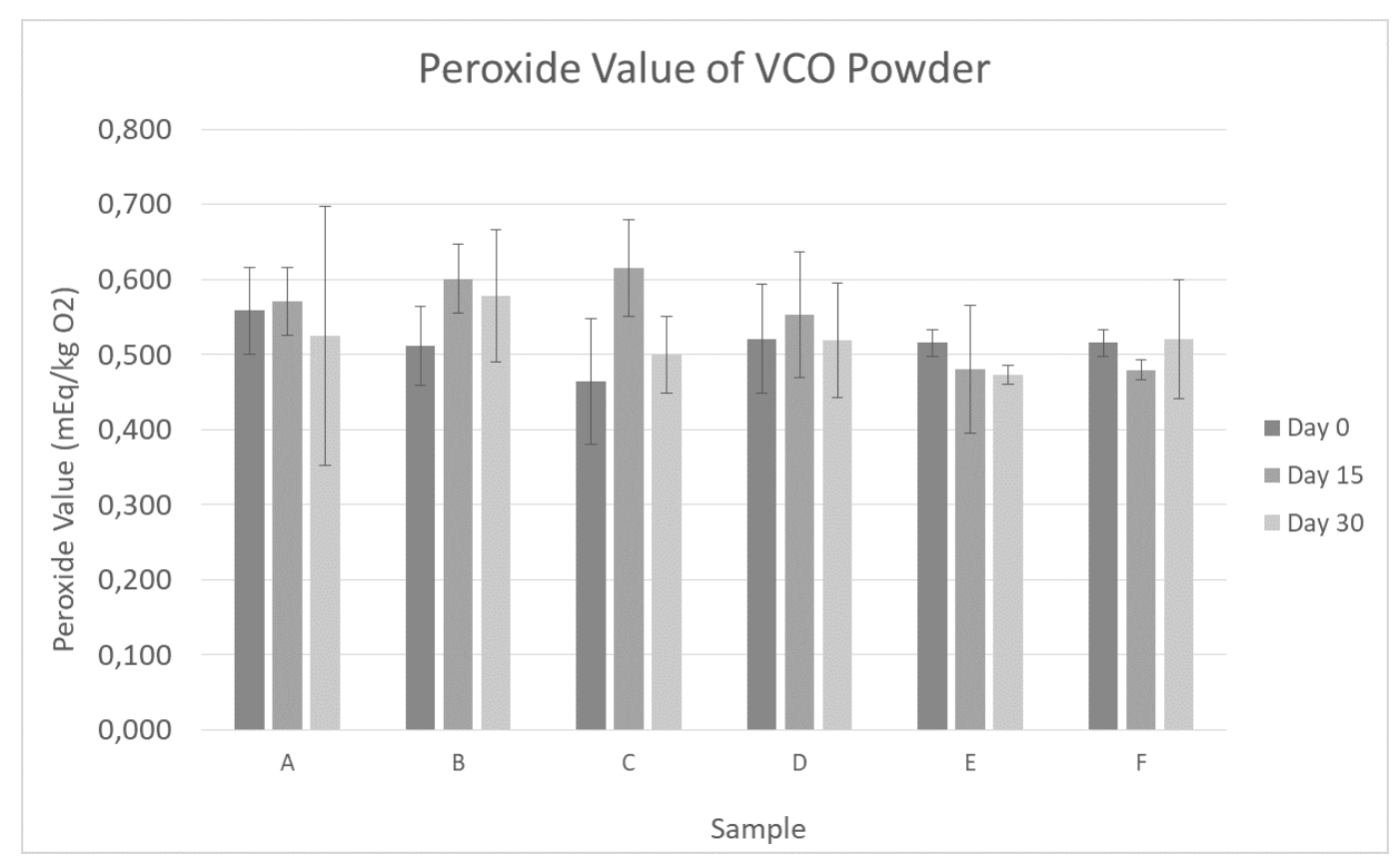

Figure 4. Peroxide value of VCO powder from Pickering emulsion with $M C C$ and different drying techniques during storage. $\mathrm{A}=\mathrm{VCO}+$ Tween $80+\mathrm{MCC}$ by spray drying; $\mathrm{B}=\mathrm{VCO}+$ Tween $80+\mathrm{MCC}$ by freeze drying; $\mathrm{C}=\mathrm{VCO}+$ Tween $80+\mathrm{MCC}$ by vacuum drying; $D=V C O+M C C$ by spray drying; $E=V C O+M C C$ by freeze drying; $F=V C O+M C C$ by vacuum drying. 
vacuum-dried VCO powder depicted the lowest peroxide value on day zero. Exposure to high temperatures of heat during the spray drying process could be the reason for accelerated oxidation, resulting in high peroxide formation in the sample (Anwar and Kunz, 2011). The vacuum process helped to minimize the oxygen that was contacted with the sample, so it prevented peroxide formation. However, peroxide values from all drying techniques did not differ significantly because basically VCO only contained a small amount of unsaturated fatty acids (about 10\%), which could be easily oxidized (Nurhasanah et al., 2019).

During storage, the peroxide value of VCO powder first depicted an increase on the 15th day then a decrease on the 30th day. Similar trends were obtained in different VCO powder samples. These results indicated that the oxidation would gradually increase to reach a peak, then it would decrease. However, the increase in peroxide value on the 15th day tended to be higher in vacuumdried VCO powder, and the lowest increase was observed in spray-dried VCO powder. Previous study conducted by Anwar and Kunz (2011) established that spray-dried powder tended to be unstable due to the presence of pro-oxidants at high temperatures, which could result in rapid peroxide decomposition after its formation. Therefore, only a slight increase in peroxide value during the 15 days of storage was observed compared to other dried samples.

The stability of VCO powder during storage was also influenced by several other factors, such as particle morphology and surface oil (Tolun et al., 2016). VCO powders obtained from freeze drying (samples B and E) and vacuum drying (samples $\mathrm{C}$ and $\mathrm{F}$ ) had an irregular morphology. As a result, the surface area was larger, so that it was more likely to be exposed to oxidation than fine particles (Pereira et al., 2019; Tolun et al., 2016). In addition, the freeze- and vacuum-dried VCO powders had high porosity and large cavities. These conditions facilitated the diffusion of oxygen on particles' surface and even the particles in surface, so that oxygen easily decomposed the non-encapsulated oil (Anwar and Kunz, 2011). Moreover, the freeze- and vacuum-dried VCO powders had a higher surface oil than the spray-dried VCO powder. Therefore, this could be one of the reasons for high increase in peroxide value on the 15th day of storage because surface oil tended to be oxidized more easily (Condori et al., 2011).

A different trend was observed in sample $\mathrm{E}$ of $\mathrm{VCO}$ powder, where its peroxide value depicted a downward trend up to the 30th day of storage. Sample F of VCO powder also depicted a decrease in peroxide value on the 15th day, and then an increase occurred on the 30th day of storage. Decrease in peroxide value during storage was because only a few new peroxides were formed compared to high degradation rate, resulting in secondary oxidation products in the form of aldehyde and ketone compounds (Ketaren, 1986). Some of the main aldehyde compounds produced from secondary oxidation were n-alkanal, trans-2-alkenes, 4-hydroxy-trans-2-alkenes and malondialdehyde (Chaijan and Panpipat, 2017). These aldehyde compounds would undergo an oxidation process to form carboxylic acids, which belong to the free fatty acid group. Hydrogen present in this carboxylic acid would form fatty acid radicals that react with oxygen to again produce peroxides during storage (Widodo et al., 2020). This increased the peroxide value of sample F on the 30th day of storage.

VCO powder obtained from emulsion with Tween 80 and MCC (samples A-C) also demonstrated a higher increase in peroxide value on the 15th day of storage. This could be due to the use of Tween 80 , which belonged to the triglyceride group, allowing the fatty acid components of Tween 80 to be oxidized during storage, resulting in a higher peroxide value compared to the nonTween 80 samples.

\section{Particle size of rehydrated VCO powder}

As observed in Table 2, all rehydrated VCO powders had a slight increase in the particle size compared with their emulsions' droplet size but not different significantly (Table 1). These results indicated that the emulsion systems had the possibility of slight coalescence because of heating and freezing during the microencapsulation process.

All rehydrated VCO powders had the same PDI value, which was still below 0.30 , indicating that there hydrated dried particles were homogeneous. However, the rehydrated freeze-dried VCO powder from both emulsions depicted higher PDI values than other dried samples with the same emulsion treatment. These phenomena occurred due to the greater coalescence process during freezing than heating so that a higher PDI was obtained (Lin et al., 2007).

\section{Dissolving time}

Dissolving time is the time required for all particles to dissolve homogeneously in solvent through stirring (Pereira et al., 2019). The dissolving time is one of the parameters of microcapsule rehydration properties and is important for producing instant powder drinks. The lower the dissolving time, the better it would be for instant powder drink. As presented in Table 2, the dissolving time of $\mathrm{VCO}$ powders was in the range of 78.75-258.50 sec, while the dissolving time of microencapsulated pink 
pepper essential oil observed by Pereira et al. (2019) was in the range of 329-351 sec. Relatively fast dissolving time of VCO powders in water is one of the important requirements of the food industry, because it can expand the possible use of VCO in food products that are insoluble in water in their original form (Pereira et al., 2019).

The dissolving time is influenced by different structural characteristics of VCO powders related to matrix and drying conditions (Farias and Ratti, 2009; Rahman and Perera, 2007). Freeze-dried VCO powder (samples B and E) had the minimum dissolving time compared to other drying principles whereas vacuum-dried VCO powder had the longest dissolving time. This was due to the high porosity of freeze-dried VCO powder, as depicted in Figure 2, so that it had the shortest dissolving time because particle porosity also played an important role in powder rehydration (Farias and Ratti, 2009; Fernandes et al., 2013; Stapley, 2008). Similar results were observed by Karthik and Anandharamakrishnan (2013). The spraydried VCO powder had a longer dissolving time than freeze-dried VCO powder but faster than vacuum-dried VCO powder. This was in line with particle morphology, because the spray-dried VCO powder had nonporous particles compared to freeze-dried VCO powder, but it also had a larger surface area than vacuum-dried VCO powder, so that its dissolving time was in between freezeand vacuum-dried VCO powders. Meanwhile, the vacuum-dried VCO powder, with a sticky characteristic, had the smallest surface area among all VCO powders obtained from different drying techniques. It tended to stick together due to wetness of surface oil, affecting the wettability of particles, resulting in the longest dissolving time in samples $\mathrm{C}$ and $\mathrm{F}$.

VCO powders from emulsion with Tween 80 and MCC (samples A-C) had a faster dissolving time because of Tween 80, which formed foam in the emulsion system, resulting in a porous microcapsule (Ngamwonglumlert and Devahastin, 2017). The high porous structure resulted in high solvent penetration of particles, hence shorter time required to dissolve all particles homogeneously in the solvent (Farias and Ratti, 2009).

\section{Conclusion}

The Pickering emulsion method (with or without Tween 80) could be used to produce VCO powders of good characteristics, which, of course, were also affected by drying techniques. Usage of MCC resulted in thicker emulsion system. However, addition of Tween 80 decreased emulsion viscosity (but both emulsion treatments had a good stability of up to 21 days of storage) and resulted in a emulsion of smaller droplet size than without addition of Tween 80 . So did the drying techniques. Spray drying produced VCO powder with the lowest drying yield (44.98-53.86\%), had bright and white spherical shape particles, smooth surface and no pores, but with some dents on the particle surface. It has the highest microencapsulation efficiency $(33.49 \pm 1.59 \%)$ and peroxide value on day zero $\left(0.558 \pm 0.058 \mathrm{mEq} \mathrm{O}_{2} / \mathrm{kg}\right)$ with not too slow dissolving time. Freeze drying produced VCO powder with the highest drying yield (94.03-96.43\%), had bright and white wrinkled sponge-like particles with an irregular and very porous surfaces. It had the smallest rehydrated particle size $(1.4820 \pm 0.0139 \mu \mathrm{m})$ and the fastest dissolving time in solvent $(78.75 \pm 2.47$ $\mathrm{sec})$, with the highest peroxide value on the 30th day of storage $\left(0.578 \pm 0.088 \mathrm{mEq} \mathrm{O}_{2} / \mathrm{kg}\right)$. Vacuum drying produced VCO powder with a more yellowish color with angular shape particles with large cavities on the surface. It had the lowest moisture content $(2.19 \pm 0.56 \%)$, the highest peroxide value on the 15th day of storage $\left(0.615 \pm 0.065 \mathrm{mEq} \mathrm{O}_{2} / \mathrm{kg}\right)$, and the longest dissolving time $(258.20 \pm 12.73 \mathrm{sec})$.

Based on the results, spray drying was the best technique to produce VCO powder with good characteristics compared to other techniques; hence, Sample A (VCO emulsion using Tween 80 and MCC with spray drying) had no creaming index up to 21 days of storage, had small size of emulsion droplet, and bright and white color VCO powder. It had spherical shape particles, high microencapsulation efficiency and not too slow dissolving time. Therefore, spray drying technique is worth applying in various applications of microencapsulation than other two drying techniques. Overall, the characteristics of VCO powders obtained in this study were quite good, but had low microencapsulation efficiency. Further research is required to study and increase the concentration of solid emulsifier and to replace $\mathrm{MCC}$ with $\mathrm{CNC}$ with a lower concentration but providing better stability and higher microencapsulation efficiency to VCO powder so that it could be used as a non-dairy creamer in accordance with quality requirements and consumer requirements.

\section{References}

Ahn, J.-H., Kim, Y.-P., Lee, Y.-M., Seo, E.-M., Lee, K.-W., \& Kim, H.-S. (2008). Optimization of microencapsulation of seed oil by response surface methodology. Food Chemistry, 107(1), 98-105. https://doi.org/10.1016/j.foodchem.2007.07.067

Ahsan, H. M., Zhang, X., Liu, Y., Wang, Y., Li, Y., Li, B., Wang, J., \& Liu, S. (2020). Stable cellular foams and oil powders derived from methylated microcrystalline cellulose stabilized pickering emulsions. In Professor Pete Williams DSc PhD (Ed.), Food Hydrocolloids (Vol. 104). Elsevier Ltd. https://doi.org/10.1016/j. foodhyd.2020.105742

Akhtar, M., Murray, B. S., Afeisume, E. I., \& Khew, S. H. (2014). Encapsulation of flavonoid in multiple emulsion using spinning 
disc reactor technology. Food Hydrocolloids, 34, 62-67. https:// doi.org/10.1016/j.foodhyd.2012.12.025

Alavi, M. (2019). Modifications of microcrystalline cellulose (MCC), nanofibrillated cellulose (NFC), and nanocrystalline cellulose (NCC) for antimicrobial and wound healing applications. E-Polymers, 19(1), 103-119. https://doi.org/10.1515/ epoly-2019-0013

Alcântara, M. A., Lima, A. E. A. de, Braga, A. L. M., Tonon, R. V., Galdeano, M. C., Mattos, M. da C., Brígida, A. I. S., Rosenhaim, R., Santos, N. A. dos, \& Cordeiro, A. M. T. de M. (2019). Influence of the emulsion homogenization method on the stability of chia oil microencapsulated by spray drying. Powder Technology, 354, 877-885. https://doi.org/10.1016/j.powtec.2019.06.026

Amaral, P. H. R. do, Andrade, P. L., \& Conto, L. C. de. (2019). Microencapsulation and Its Uses in Food Science and Technology: A Review. In F. Salaun (Ed.), Microencapsulation Processes, Technologies and Industrial Applications (pp. 1-18). IntechOpen. https://doi.org/10.5772/intechopen.81997

Anandharamakrishnan, C., \& Ishwarya, S. P. (2015). Introduction to spray drying. In C. Anandharamakrishnan \& S. P. Ishwarya (Eds.), Spray Drying Techniques for Food Ingredient Encapsulation (pp. 1-36). John Wiley \& Sons Inc. https://doi. org/10.1002/9781118863985.ch1

Anwar, S. H., \& Kunz, B. (2011). The influence of drying methods on the stabilization of fish oil microcapsules: Comparison of spray granulation, spray drying, and freeze drying. Journal of Food Engineering, 105(2), 367-378. https://doi.org/10.1016/j. jfoodeng.2011.02.047

AOAC. (2005a). Association of Official Analytical Chemistry (AOAC) Official Method 963.15, Lipid Content.

AOAC. (2005b). Solids (Total) and Moisture in Flour, Method 925.10. Official Methods of Analysis, 18th Edition.

Badan Standardisasi Nasional. (2008). SNI 01-7381-2008 Minyak Kelapa Virgin (VCO) (pp. 1-28). Badan Standarisasi Nasional.

Badan Standarisasi Nasional. (2009). SNI 4444:2009 Krimer Nabati Bubuk (pp. 1-37). Badan Standarisasi Nasional.

Bai, L., Huan, S., Xiang, W., \& Rojas, O. J. (2018). Pickering emulsions by combining cellulose nanofibrils and nanocrystals: Phase behavior and depletion stabilization. Green Chemistry, 20(7), 1571-1582. https://doi.org/10.1039/c8gc00134k

Bazyma, L. A., \& Kutovoy, V. A. (2005). Vacuum drying and hybrid technologies. Stewart Postharvest Review, 1(4), 1-4. https://doi. org/10.2212/spr.2005.4.7

Carneiro, H. C. F., Tonon, R. V., Grosso, C. R. F., \& Hubinger, M. D. (2013). Encapsulation efficiency and oxidative stability of flaxseed oil microencapsulated by spray drying using different combinations of wall materials. Journal of Food Engineering, 115(4), 443-451. https://doi.org/10.1016/j.jfoodeng.2012.03.033

Chaijan, M., \& Panpipat, W. (2017). Mechanism of Oxidation in Foods of Animal Origin. In R. Banerjee, K. A. Verma, \& M. W. Siddiqui (Eds.), Natural Antioxidants (1st ed., pp. 1-37). Taylor \& Francis Group. https://doi.org/10.1201/9781315365916-2

Condori, S. Q., Saldaña, M. D. A., \& Temelli, F. (2011). Microencapsulation of flax oil with zein using spray and freeze drying. LWT - Food Science and Technology, 44(9), 1880-1887. https://doi.org/10.1016/j.lwt.2011.01.005
Costa, Medronho, Filipe, Mira, Lindman, Edlund, \& Norgren. (2019). Emulsion Formation and Stabilization by Biomolecules: The Leading Role of Cellulose. Polymers, 11(10), 1570. https:// doi.org/10.3390/polym11101570

Dadi, D. W., Emire, S. A., Hagos, A. D., \& Eun, J. B. (2020). Physical and Functional Properties, Digestibility, and Storage Stability of Spray- and Freeze-Dried Microencapsulated Bioactive Products from Moringa stenopetala Leaves Extract. Industrial Crops and Products, 156(2020), 1-10. https://doi.org/10.1016/j. indcrop.2020.112891

Das S., \& Chaudhury A. (2011). Recent Advances in Lipid Nanoparticle Formulations with Solid Matrix for Oral Drug Delivery. AAPS PharmSciTech. 12(1): 62-76. https://doi.org/ 10.1208/s12249-010-9563-0

Dhar, N., Akhlaghi, S. P., \& Tam, K. C. (2012). Biodegradable and biocompatible polyampholyte microgels derived from chitosan, carboxymethyl cellulose and modified methyl cellulose. Carbohydrate Polymers, 87(1), 101-109. https://doi. org/10.1016/j.carbpol.2011.07.022

Díaz, C. B.-, Navarrete, M. O.-, Añual, M. S.-, Calderón, F. L.-, \& Bustamante, M. (2020). Food-grade Pickering emulsion as a novel astaxanthin encapsulation system for making powder-based products: Evaluation of astaxanthin stability during processing, storage, and its bioaccessibility. Food Research International, 134, 109244. https://doi.org/10.1016/j. foodres.2020.109244

Esparza, Y., Ngo, T. D., \& Boluk, Y. (2020). Preparation of powdered oil particles by spray drying of cellulose nanocrystals stabilized Pickering hempseed oil emulsions. Colloids and Surfaces A: Physicochemical and Engineering Aspects, 598(March), 124823. https://doi.org/10.1016/j.colsurfa.2020.124823

Farias, M. A., \& Ratti, C. (2009). Dehydration of Foods : General Concepts. In C. Ratti (Ed.), Advances in Food Dehydration (pp. 1-36). Taylor \& Francis Ltd.

Fernandes, R. V. de B., Borges, S. V., \& Botrel, D. A. (2013). Influence of spray drying operating conditions on microencapsulated rosemary essential oil properties. Ciência $e$ Tecnologia de Alimentos, 33, 171-178. https://doi.org/10.1590/ S0101-20612013000500025

Frascareli, E. C., Silva, V. M., Tonon, R. V., \& Hubinger, M. D. (2012). Effect of process conditions on the microencapsulation of coffee oil by spray drying. Food and Bioproducts Processing, 90(3), 413-424. https://doi.org/10.1016/j.fbp.2011.12.002

Gallardo, G., Guida, L., Martinez, V., López, M. C., Bernhardt, D., Blasco, R., Pedroza-Islas, R., \& Hermida, L. G. (2013). Microencapsulation of linseed oil by spray drying for functional food application. Food Research International, 52(2), 473-482. https://doi.org/10.1016/j.foodres.2013.01.020

Gomes, A., Costa, A. L. R., \& Cunha, R. L. (2018). Impact of oil type and WPI/Tween 80 ratio at the oil-water interface: Adsorption, interfacial rheology and emulsion features. Colloids and Surfaces B: Biointerfaces, 164, 272-280. https://doi.org/10.1016/j. colsurfb.2018.01.032

Gong, Z., Zhang, M., \& Sun, J. (2007). Physico-chemical properties of cabbage powder as affected by drying methods. Drying Technology, 25(5), 913-916. https://doi.org/10.1080/07373930701372239 
Hadnadev, T. D., Dokić, P., Krstonošić, V., \& Hadnadev, M. (2013). Influence of oil phase concentration on droplet size distribution and stability of oil-in-water emulsions. European Journal of Lipid Science and Technology, 115(3), 313-321. https://doi. org/10.1002/ejlt.201100321

Hee, Y. Y., Tan, C. P., Rahman, R. A., Adzahan, N. M., Lai, W. T., \& Chong, G. H. (2015). Influence of Different Wall Materials on the Microencapsulation of Virgin Coconut Oil by Spray Drying. International Journal of Food Engineering, 11(1), 61-69. https:// doi.org/10.1515/ijfe-2014-0215

Hee, Y. Y., Tan, C. P., Rahman, R. A., Noranizan, M., Smith Jr, R. L., \& Chong, G. H. (2017). Production of virgin coconut oil microcapsules from oil-in-water emulsion with supercritical carbon dioxide spray drying. The Journal of Supercritical Fluids, 130, 118-124. https://doi.org/10.1016/j.supflu.2017.07.037

Hirschle, P., Preiß, T., Auras, F., Pick, A., Völkner, J., Valdepérez, D., Witte, G., Parak, W. J., Rädler, J. O., \& Wuttke, S. (2016). Exploration of MOF nanoparticle sizes using various physical characterization methods-is what you measure what you get? CrystEngComm, 18(23), 4359-4368. https://doi.org/10.1039/ c6ce00198j

Horszwald, A., Julien, H., \& Andlauer, W. (2013). Characterisation of Aronia powders obtained by different drying processes. Food Chemistry, 141(3), 2858-2863. https://doi.org/10.1016/j. foodchem.2013.05.103

Hu, Z., Ballinger, S., Pelton, R., \& Cranston, E. D. (2015). Surfactantenhanced cellulose nanocrystal Pickering emulsions. Journal of Colloid and Interface Science, 439, 139-148. https://doi. org/10.1016/j.jcis.2014.10.034

Iijima, H., \& Takeo, K. (2000). Microcrystalline Cellulose: An Overview. In G. O. Phillips \& P. A. Williams (Eds.), Handbook of Hydrocolloids (pp. 331-346). Woodhead Publishing Ltd.

ISO, \& IDF. (2006). Milk Fat - Determination of Peroxide Value (ISO 3976 - IDF 74) (2nd ed., pp. 1-13). ISO and IDF.

Joslyn, M. A., \& Sano, T. (1956). The Formation and Decomposition of Green Pigment in Crushed Garlic Tissue. Journal of Food Science, 21(2), 170-183. https://doi.org/10.1111/j.1365-2621.1956.tb16 908.x

Kamsiati, E. (2006). Pembuatan Bubuk Sari Buah Tomat (Licopersicon esculentum) dengan Metode "Foam-Mat Drying." Teknologi Pertanian, 7(2), 113-119.

Kargar, M., Fayazmanesh, K., Alavi, M., Spyropoulos, F., \& Norton, I. T. (2012). Investigation into the potential ability of Pickering emulsions (food-grade particles) to enhance the oxidative stability of oil-in-water emulsions. Journal of Colloid and Interface Science, 366(1), 209-215. https://doi.org/10.1016/j. jcis.2011.09.073

Karthik, P., \& Anandharamakrishnan, C. (2013). Microencapsulation of Docosahexaenoic Acid by Spray-Freeze-Drying Method and Comparison of its Stability with Spray-Drying and FreezeDrying Methods. Food and Bioprocess Technology, 6(10), 27802790. https://doi.org/10.1007/s11947-012-1024-1

Ketaren, S. (1986). Pengantar Teknologi Minyak dan Lemak Pangan. UI Press.

Klinjapo, R., \& Krasaekoopt, W. (2018). Microencapsulation of Color and Flavor in Confectionery Products. In A. M. Grumezescu \&
H. A. Maria (Eds.), Natural and Artificial Flavoring Agents and Food Dyes (pp. 457-494). Elsevier Inc. https://doi.org/10.1016/ B978-0-12-811518-3.00014-4

Kuck, L. S., \& Noreña, C. P. Z. (2016). Microencapsulation of grape (Vitis labrusca var. Bordo) skin phenolic extract using gum Arabic, polydextrose, and partially hydrolyzed guar gum as encapsulating agents. Food Chemistry, 194, 569-576. https:// doi.org/10.1016/j.foodchem.2015.08.066

Lim, A. S. L., \& Roos, Y. H. (2017). Carotenoids stability in spray dried high solids emulsions using layer-by-layer (LBL) interfacial structure and trehalose-high DE maltodextrin as glass former. Journal of Functional Foods, 33, 32-39. https://doi. org/10.1016/j.jff.2017.03.006

Lin, C., He, G., Li, X., Peng, L., Dong, C., Gu, S., \& Xiao, G. (2007). Freeze/thaw induced demulsification of water-in-oil emulsions with loosely packed droplets. Separation and Purification Technology, 56(2), 175-183. https://doi.org/10.1016/j.seppur.2007.01.035

Liu, Y., Zhao, Y., \& Feng, X. (2008). Exergy analysis for a freeze-drying process. Applied Thermal Engineering, 28(7), 675-690. https://doi.org/10.1016/j.applthermaleng.2007.06.004

Mayasari, E., Rahayuni, T., \& Manalu, J. (2019). Pengaruh Formulasi Maltodekstrin Dan Tween 80 Pada Karakteristik Fisikokimia Bumbu Herbal Instan. Pro Food, 5(2), 479. https://doi. org/10.29303/profood.v5i2.102

McClements, D. J. (2005). Food Emulsions: Principles, Practices, and Techniques. In D. J. McClements (Ed.), Food Emulsions: Principles, Practices, and Techniques, Sec (2nd ed.). Taylor \& Francis Inc.

McNamee, B. F., O’Riorda, E. D., \& O'Sullivan, M. (1998). Emulsification and Microencapsulation Properties of Gum Arabic. Journal of Agricultural and Food Chemistry, 46(11), 4551-4555. https://doi.org/10.1021/jf9803740

Melgosa, R., Román, Ó. B., Sanz, M. T., Paz, E. de, \& Beltrán, S. (2019). Omega-3 encapsulation by PGSS-drying and conventional drying methods. Particle characterization and oxidative stability. Food Chemistry, 270, 138-148. https://doi. org/10.1016/j.foodchem.2018.07.082

Michalska, A., \& Lech, K. (2018). The Effect of Carrier Quantity and Drying Method on the Physical Properties of Apple Juice Powders. Beverages, 4(1), 2. https://doi.org/10.3390/ beverages 4010002

Moreno, T., de Paz, E., Navarro, I., Rojo, S. R., Matías, A., Duarte, C., Buenhombre, M. S., \& Cocero, M. J. (2016). Spray Drying Formulation of Polyphenols-Rich Grape Marc Extract: Evaluation of Operating Conditions and Different Natural Carriers. Food and Bioprocess Technology, 9, 2046-2058. https:// doi.org/10.1007/s11947-016-1792-0

Mubarak, S. (2017). Pengaruh Penyimpanan Minyak Jelantah Terhadap Bilangan Peroksida. Jurnal Ilmiah Kesehatan Iqra, 5(1), 42-47.

Muhamad, I. I., Jusoh, Y. M. M., Nawi, N. M., Aziz, A. A., Padzil, A. M., \& Lian, H. L. (2018). Advanced Natural Food Colorant Encapsulation Methods: Anthocyanin Plant Pigment. In M. A. Grumezescu \& H. A. Maria (Eds.), Natural and Artificial Flavoring Agents and Food Dyes (pp. 495-526). Elsevier. https:// doi.org/10.1016/B978-0-12-811518-3.00015-6 
Mutlu, C., Koç, A., \& Erbaş, M. (2020). Some physical properties and adsorption isotherms of vacuum-dried honey powder with different carrier materials. $L W T, 134,110166$. https://doi. org/10.1016/j.lwt.2020.110166

Nedovic, V., Kalusevic, A., Manojlovic, V., Levic, S., \& Bugarski, B. (2011). An overview of encapsulation technologies for food applications. Procedia Food Science, 1, 1806-1815. https://doi. org/10.1016/j.profoo.2011.09.265

Ngamwonglumlert, L., \& Devahastin, S. (2017). Microstructure and its relationship with quality and storage stability of dried foods. In S. Devahastin (Ed.), Food Microstructure and Its Relationship with Quality and Stability. Elsevier Ltd. https://doi.org/10.1016/ B978-0-08-100764-8.00008-3

Nurhadi, B., Andoyo, R., Mahani, \& Indiarto, R. (2012). Study the properties of honey powder produced from spray drying and vacuum drying method. International Food Research Journal, 19(3), 849-854.

Nurhadi, B., \& Roos, Y. H. (2017). Influence of anti-caking agent on the water sorption isotherm and flow-ability properties of vacuum dried honey powder. Journal of Food Engineering, 210, 76-82. https://doi.org/10.1016/j.jfoodeng.2017.04.020

Nurhasanah, S., Wulandari, N., Munarso, S. J., \& Hariyadi, P. (2019). Production of structured lipids rich in triacylglycerols containing medium-chain fatty acids and unsaturated fatty acids at the Sn-2 position through enzymatic interesterification. International Journal on Advanced Science, Engineering and Information Technology, 9(5), 1624-1630. https://doi. org/10.18517/ijaseit.9.5.10076

Parikh, D. M. (2015). Vacuum Drying: Basics and application. Chemical Engineering (United States), 122(4), 48-54.

Parrish, C. R. (2017). The Use of Medium-Chain Triglycerides in Gastrointestinal Disorders. Nutrition Issues in Gastroenterology, Series \#160, 160(February), 20-28.

Partanen, R., Raula, J., Seppaünen, R., Buchert, J., Kauppinen, E., \& Forssell, P. (2008). Effect of Relative Humidity on Oxidation of Flaxseed Oil in Spray Dried Whey Protein Emulsions. Journal of Agricultural and Food Chemistry, 56(14), 5717-5722. https:// doi.org/10.1021/jf8005849

Pasrija, D., Ezhilarasi, P. N., Indrani, D., \& Anandharamakrishnan, C. (2015). Microencapsulation of green tea polyphenols and its effect on incorporated bread quality. LWT - Food Science and Technology, 64(1), 289-296. https://doi.org/10.1016/j. lwt.2015.05.054

Patil, U., Benjakul, S., Prodpran, T., Senphan, T., \& Cheetangdee, N. (2016). Characteristics and quality of virgin coconut oil as influenced by maturity stages. Carpathian Journal of Food Science and Technology, 8(4), 103-115.

Pereira, A. R. L., Cattelan, M. G., \& Nicoletti, V. R. (2019). Microencapsulation of pink pepper essential oil: Properties of spray-dried pectin/SPI double-layer versus SPI single-layer stabilized emulsions. Colloids and Surfaces A: Physicochemical and Engineering Aspects, 581(August), 123806. https://doi. org/10.1016/j.colsurfa.2019.123806

Pichot, R., Spyropoulos, F., \& Norton, I. T. (2010). O/W emulsions stabilised by both low molecular weight surfactants and colloidal particles: The effect of surfactant type and concentration.
Journal of Colloid and Interface Science, 352(1), 128-135. https://doi.org/10.1016/j.jcis.2010.08.021

Piwińska, M., Wyrwisz, J., Kurek, M., \& Wierzbicka, A. (2015). Hydration and physical properties of vacuum-dried durum wheat semolina pasta with high-fiber oat powder. $L W T$ Food Science and Technology, 63(1), 647-653. https://doi. org/10.1016/j.lwt.2015.03.022

Rahman, M. S., \& Perera, C. O. (2007). Drying and Food Preservation. In M. S. Rahman (Ed.), Handbook of Food Preservation (2nd ed., pp. 403-432). Taylor \& Francis Inc.

Rajabi, H., Ghorbani, M., Jafari, S. M., Sadeghi, A., \& Rajabzadeh, G. (2015). Retention of saffron bioactive components by spray drying encapsulation using maltodextrin, gum Arabic and gelatin as wall materials. Food Hydrocolloids, 51, 327-337. https://doi. org/10.1016/j.foodhyd.2015.05.033

Raman, A. K. Y., \& Aichele, C. P. (2020). Influence of non-ionic surfactant addition on the stability and rheology of particlestabilized emulsions. Colloids and Surfaces A: Physicochemical and Engineering Aspects, 585, 124084. https://doi.org/10.1016/j. colsurfa.2019.124084.

Ré, M. I. (1998). Microencapsulation by Spray Drying. Drying Technology, 16(6), 1195-1236. https://doi.org/10.1080/0737393 9808917460

Reis, F. R. (2014). Studies on Conventional Vacuum Drying of Foods (pp. 7-18). https://doi.org/10.1007/978-3-319-08207-3_2

Román, Ó. B., Sanz, T., \& Beltrán, S. (2020). Microencapsulation of rice bran oil using pea protein and maltodextrin mixtures as wall material. Heliyon, 6(4), e03615. https://doi.org/10.1016/j.heliyon.2020.e03615

Sansone, F., Mencherini, T., Picerno, P., D’Amore, M., Aquino, R. P., \& Lauro, M. R. (2011). Maltodextrin/pectin microparticles by spray drying as carrier for nutraceutical extracts. Journal of Food Engineering, 105(3), 468-476. https://doi.org/10.1016/j. jfoodeng.2011.03.004

Sarungallo, Z. L., Santoso, B., Roreng, M. K., \& Murni, V. (2019). Karakteristik Mutu Mikroenkapsulat Minyak Buah Merah (Pandanus conoideus) Dengan Perbandingan Konsentrasi Bahan Pengemulsi dan Bahan Pelapis. 5(2).

Shamaei, S., Seiiedlou, S. S., Aghbashlo, M., Tsotsas, E., \& Kharaghani, A. (2017). Microencapsulation of walnut oil by spray drying: Effects of wall material and drying conditions on physicochemical properties of microcapsules. Innovative Food Science \& Emerging Technologies, 39, 101-112. https://doi. $\operatorname{org} / 10.1016 / j$.ifset.2016.11.011

Smrdel, P., Bogataj, M., Zega, A., Planinšek, O., \& Mrhar, A. (2008). Shape optimization and characterization of polysaccharide beads prepared by ionotropic gelation. Journal of Microencapsulation, 25(2), 90-105. https://doi. org/10.1080/02652040701776109

Soottitantawat, A., Bigeard, F., Yoshii, H., Furuta, T., Ohkawara, M., \& Linko, P. (2005). Influence of emulsion and powder size on the stability of encapsulated d-limonene by spray drying. Innovative Food Science E Emerging Technologies, 6(1), 107-114. https:// doi.org/10.1016/j.ifset.2004.09.003

Stapley, A. G. F. (2008). Freeze drying, in: Evans J. A. (Ed.). Frozen Food Science and Technology, Blackwell, Oxford, UK, 248-275. 
Tinay, I. A. El, \& Ismail, A. H. (1985). Effect of some additives and processes on the characteristics of agglomerated and granulated spray-dried Roselle powder, Acta Aliment. In Hungaricae 14 (pp. 238-295).

Tolun, A., Altintas, Z., \& Artik, N. (2016). Microencapsulation of grape polyphenols using maltodextrin and gum arabic as two alternative coating materials: Development and characterization. Journal of Biotechnology, 239, 23-33. https://doi. org/10.1016/j.jbiotec.2016.10.001

Tonon, R. V., Brabet, C., \& Hubinger, M. D. (2008). Influence of process conditions on the physicochemical properties of açai (Euterpe oleraceae Mart.) powder produced by spray drying. Journal of Food Engineering, 88(3), 411-418. https://doi. org/10.1016/j.jfoodeng.2008.02.029

Tonon, R. V., Pedro, R. B., Grosso, C. R. F., \& Hubinger, M. D. (2012). Microencapsulation of Flaxseed Oil by Spray Drying: Effect of Oil Load and Type of Wall Material. Drying Technology, 30(13), 1491-1501. https://doi.org/10.1080/07373937.2012.696227

Vashisth, C., Whitby, C. P., Fornasiero, D., \& Ralston, J. (2010). Interfacial displacement of nanoparticles by surfactant molecules in emulsions. Journal of Colloid and Interface Science, 349(2), 537-543. https://doi.org/10.1016/j.jcis.2010.05.089

Vicente, J., Pereira, L. J. B., Bastos, L. P. H., Carvalho, M. G. de, \& Rojas, E. E. G. (2018). Effect of xanthan gum or pectin addition on Sacha Inchi oil-in-water emulsions stabilized by ovalbumin or tween 80: Droplet size distribution, rheological behavior and stability. International Journal of Biological Macromolecules, 120, 339-345. https://doi.org/10.1016/j.ijbiomac.2018.08.041

Wei, Z., Cheng, J., \& Huang, Q. (2019). Food-grade Pickering emulsions stabilized by ovotransferrin fibrils. Food Hydrocolloids, 94, 592-602. https://doi.org/10.1016/j.foodhyd.2019.04.005

Widodo, H., Adhani, L., Solihatun, Prastya, M., \& Annisa, A. (2020). Pemanfaatan Minyak Cengkeh Sebagai Antioksidan Alami untuk Menurunkan Bilangan Peroksida Pada Produk Minyak Goreng. Jurnal Penelitian Dan Karya Ilmiah Lembaga Penelitian Universitas Trisakti, 5(1), 77-90.

Wilkowska, A., Czyżowska, A., Ambroziak, W., \& Adamiec, J. (2017). Structural, physicochemical and biological properties of spray-dried wine powders. Food Chemistry, 228, 77-84. https:// doi.org/10.1016/j.foodchem.2017.01.115
Xie, J., Luo, Y., Chen, Y., Liu, Y., Ma, Y., Zheng, Q., Yue, P., \& Yang, M. (2019). Redispersible Pickering emulsion powder stabilized by nanocrystalline cellulose combining with cellulosic derivatives. Carbohydrate Polymers, 213, 128-137. https://doi. org/10.1016/j.carbpol.2019.02.064

Xu, D., Zhang, J., Cao, Y., Wang, J., \& Xiao, J. (2016). Influence of microcrystalline cellulose on the microrheological property and freeze-thaw stability of soybean protein hydrolysate stabilized curcumin emulsion. LWT - Food Science and Technology, 66, 590-597. https://doi.org/10.1016/j.lwt.2015. 11.002

Yam, K. L., \& Papadakis, S. E. (2004). A simple digital imaging method for measuring and analyzing color of food surfaces. Journal of Food Engineering, 61(1), 137-142. https://doi. org/10.1016/S0260-8774.(03)00195-X

Yanuwar, W., Widjanarko, S. B., \& Wahono, T. (2007). Characteristics and antioxidant stability of red fruit (Pandanus conoideus Lam) protein based microcapsule. Jurnal Teknologi Pertanian, 8(2), 127-135.

Zhang, M., Yang, B., Liu, W., \& Li, S. (2017). Influence of hydroxypropyl methylcellulose, methylcellulose, gelatin, poloxamer 407 and poloxamer 188 on the formation and stability of soybean oil-in-water emulsions. Asian Journal of Pharmaceutical Sciences, 12(6), 521-531. https://doi.org/10.1016/j.ajps.2017. 05.009

Zhang, R., Zhou, L., Li, J., Oliveira, H., Yang, N., Jin, W., Zhu, Z., Li, S., \& He, J. (2020). Microencapsulation of anthocyanins extracted from grape skin by emulsification/internal gelation followed by spray/freeze-drying techniques: Characterization, stability and bioaccessibility. LWT, 123, 109097. https://doi. org/10.1016/j.lwt.2020.109097

Zhang, S., Chen, J., Yin, X., Wang, X., Qiu, B., Zhu, L., \& Lin, Q. (2017). Microencapsulation of tea tree oil by spray-drying with methyl cellulose as the emulsifier and wall material together with chitosan/alginate. Journal of Applied Polymer Science, 134(13), 1-10. https://doi.org/10.1002/app.44662

Zhong, Q., Jin, M., Davidson, P. M., \& Zivanovic, S. (2009). Sustained release of lysozyme from zein microcapsules produced by a supercritical anti-solvent process. Food Chemistry, 115(2), 697700. https://doi.org/10.1016/j.foodchem.2008.12.063 